\title{
Detailed Speciation and Reactivity Characterization of Fuel-Specific In-Cylinder Reforming Products and the Associated Impact on Engine Performance
}

\author{
Benjamin Wolk ${ }^{1 *}$, Isaac Ekoto ${ }^{1}$, William F. Northrop ${ }^{2}$, Kai Moshammer ${ }^{1}$, Nils Hansen ${ }^{1}$ \\ ${ }^{1}$ Combustion Research Facility, Sandia National Laboratories, 7011 East Ave., Livermore, CA 94550 \\ ${ }^{2}$ Dept. of Mechanical Engineering, University of Minnesota, 111 Church St. SE, Minneapolis MN 55455, USA
*Corresponding author: Benjamin Wolk
bmwolk@sandia.gov
P.O. Box 969, MS 9053
Livermore, CA 94551 USA
+1 (925) 294-6910

Color preference: Online only

(C) 2016. This manuscript version is made available under the Elsevier user license

http://www.elsevier.com/open-access/userlicense/1.0/ 


\begin{abstract}
:
In-cylinder reforming of a gasoline pilot fuel injection during the negative valve overlap (NVO) period of an engine cycle can be used to alter the fuel-air mixture reactivity in low-temperature gasoline combustion (LTGC). In the present study, the impact of the NVO reformate on main-period engine performance was evaluated experimentally for four single-component surrogate gasoline fuels (isooctane, n-heptane, ethanol, and 1-hexene) using a custom alternate-fire sequence. For each fuel, the NVO injection mass was held constant as the main-period injection mass was varied. The constant NVO injection mass allowed the NVO reformate product stream to be separately characterized in detail using photoionization mass spectrometry (PIMS). PIMS measurements were performed to characterize the NVO reformates of the four fuels used for main-period engine performance testing, as well as two additional fuels: cyclohexane and a toluene/n-heptane blend. All experiments were conducted using a direct-injection, single-cylinder research engine equipped with a custom dump valve apparatus used to perform bulk gas sampling at the end of the NVO period. A constant volume, adiabatic, single-zone reactor model with detailed chemical kinetic mechanisms was used to evaluate the reactivity of each NVO reformate compared to the unreformed parent fuel, the impact of specific species on reformate reactivity, and to examine the factors that influence main-period engine performance. The PIMS measurements and reactor model analysis indicated that all tested fuels (except $n$-heptane) exhibit increased reformate reactivity as compared to the unreacted parent fuel through production of more reactive species, namely acetylene, acetaldehyde, propene, and allene. Main-period engine performance was impacted by changes in reactivity from the reformate fraction of total fueling and compressed temperature (through the ratio of specific heats and differences in charge cooling from the main injection). Iso-octane was found to have the largest benefit in reactivity as the reformate fraction of total fueling increased. Alternatively, increases in reactivity for ethanol were primarily due to decreased charge cooling while reactivity increases for 1-hexene were dictated by increased ratio of specific heats. This paper demonstrates that NVO-generated reformate can improve main-period reactivity through both chemical and thermal effects, although significant NVO-period heat losses reduce total-cycle engine thermal efficiency.
\end{abstract}

Keywords: Low temperature gasoline combustion; Negative valve overlap; Gasoline; Reforming; Photoionization mass spectrometry 


\section{Nomenclature}

\section{AHR/AHRR}

CA

$\mathrm{CA}_{\mathrm{NVO}}$

$\mathrm{CoV}$

EVC/EVO

$\mathrm{GC}$

HR/HRR

IMEP

ITE

IVC/IVO

LHV

LTGC

MCP

NTC

NVO

PIE

PIMS

ppm

PRF

RGF

RON

RPM

SNR

SOI

TDC

VUV

$\mathrm{m} / \mathrm{z}$

$t_{i g n}$

$T_{\text {peak }}$

$\Delta t_{i g n}(T, P)$

$\gamma$

$\varphi$
Apparent heat release/rate

Crank angle relative to main-period TDC

Crank angle relative to NVO-period TDC

Coefficient of variation

Exhaust valve close/open

Gas chromatograph

Heat release/rate

Indicated mean effective pressure

Indicated thermal efficiency

Intake valve close/open

Lower heating value

Low-temperature gasoline combustion

Micro-channel plate

Negative temperature coefficient

Negative valve overlap

Photoionization efficiency

Photoionization mass spectroscopy

Parts per million

Primary reference fuel

Residual gas fraction

Research octane number

Revolutions per minute

Signal-to-noise ratio

Start of fuel injection

Top dead center

Vacuum ultraviolet

Mass-to-charge ratio

Constant-volume ignition delay time

Peak bulk-averaged in-cylinder temperature during the NVO period

Difference in $t_{i g n}$ between neat PRF60 and the $t_{i g n}$ of $95 \%$ PRF60 $+5 \%$ by

mole of a test species at stoichiometric conditions and a given temperature $(T)$ and pressure $(P)$

Ratio of specific heats

Equivalence ratio 


\section{Introduction}

The Low-Temperature Gasoline Combustion (LTGC) strategy, where combustion is initiated via compression-induced auto-ignition of dilute charge mixtures, can reduce nitrogen oxide $\left(\mathrm{NO}_{\mathrm{x}}\right)$ and soot emissions while improving cycle thermal efficiency. The central challenge has been to achieve effective ignition control at low engine loads, where slow burn rates due to elevated dilution fractions and low incylinder temperatures can lead to partial burn or even misfire [1]. Proposed strategies to improve lowload auto-ignition control include intake air heating [2], exhaust valve re-breathing [3], spark-assist [4] and partial fuel stratification [5, 6]. However, intake heating leads to large parasitic losses and is not practical for engine transients, spark ignition is ineffective at low loads under heavy dilution, and fuel stratification can increase soot and $\mathrm{NO}_{\mathrm{x}}$ emissions due to the formation of locally rich regions.

A viable alternative is to use in-cylinder combustion or reformation of fuel injected during an auxiliary negative valve overlap (NVO) recompression period to heat the charge and alter reactivity characteristics [7-9]. Reformate speciation at the conclusion of the NVO period has been performed for a range of mixture stoichiometry, with energy analyses used to determine the tradeoffs among recovered chemical energy, NVO-period work, and NVO-period heat losses [9-11]. Moreover, it was demonstrated that partially oxidized species, when fed into the intake, can increase cycle thermodynamic efficiency through increased charge specific heat ratios [12].

For NVO periods with low amounts of excess oxygen $\left(\mathrm{O}_{2}\right)$, kinetically limited pyrolysis and partial oxidation reactions result in a reformate-rich product stream laden with small hydrocarbons, carbon monoxide $(\mathrm{CO})$, and hydrogen $\left(\mathrm{H}_{2}\right)$. Reformate speciation was previously performed through dump sampling at the conclusion of the NVO period with sample characterization by gas chromatography (GC) $[13,14]$. Although GC can effectively measure the general classifications of hydrocarbon species present in the reformate, it is less accurate at quantifying isomers with similar column elution times that have been observed to have significantly different oxidation pathways [15]. That is, GC provides sufficient information to perform a chemical energy balance of the NVO-period injected fuel, but it does 
not provide the detail needed to accurately model the impact of the reformate on auto-ignition reactivity during the main period. Additionally, the previous work by the authors $[13,14]$ did not include experimental measurements of the influence of the reformate on main-period engine performance.

In this work, the impact of NVO reformate on main-period engine performance for four singlecomponent surrogate gasoline fuels (iso-octane, n-heptane, ethanol, and 1-hexene) was evaluated using a custom alternate-fire sequence at a range of main-period injection mass. The NVO-period reformates for the four tested fuels, as well as cyclohexane and a blend of toluene/n-heptane, were separately characterized through detailed speciation using photoionization mass spectrometry (PIMS) with synchrotron-generated vacuum ultraviolet (VUV) light. A single-cylinder research engine equipped with a custom dump-valve sampling system was used for all experiments. An adiabatic, single-zone reactor model was used to evaluate the charge reactivity of the PIMS-measured reformates compared to the unreformed parent fuels (e.g. iso-octane) and to examine the factors influencing main-period engine performance.

\section{Experimental}

\subsection{Single-Cylinder Research Engine}

Engine experiments were conducted in two parts: (1) main-period engine performance measurements and (2) dump-sampling of the NVO reformate with speciation by PIMS. An optically accessible single-cylinder research engine outfitted with a pent-roof cylinder head, central direct injection, and a flat-top piston was used for all experiments. The cylinder head has one exhaust and two intake valves. All-metal components replaced quartz windows and liners for the current experiments; crevice volumes are $~ 3-4$ times larger than a comparable production engine. The Bosch, step-hole, valve covered orifice injector has 8 nozzles and a $60^{\circ}$ included angle. The 150 crank angle (CA) duration NVO recompression was centered around NVO top dead center $\left(\mathrm{TDC}_{\mathrm{NVO}}\right)$, achieved by modifying the exhaust valve closure (EVC) and intake valve opening (IVO) events (geometric recompression ratio of 5.51:1). The modified valve timing along with the use of low-lift cams ( $3 \mathrm{~mm}$ lift) resulted in $\sim 46 \%$ 
retained burned gases into the subsequent main portion of the cycle. Bulk temperatures and residual gas fractions (RGF) at EVC were calculated using a custom 1-D engine model previously described by Fitzgerald et al. [16]. The head surface temperature was monitored by an embedded thermocouple. Relevant engine geometric and operating characteristics are summarized in Table 1.

Table 1. Engine specifications and operating conditions.

\begin{tabular}{|c|c|}
\hline Displaced Volume $\left[\mathrm{cm}^{3}\right]$ & 633 \\
\hline Bore/Stroke $[\mathrm{mm}]$ & $92 / 95.25$ \\
\hline Compression Ratio & 11.3:1 \\
\hline Connecting Rod [mm] & 166.7 \\
\hline Intake Valve Open/Close [CA] & $-285 /-140$ \\
\hline Exhaust Valve Open/Close [CA] & $+140 /+285$ \\
\hline NVO Duration $[\mathrm{CA}]$ & 150 \\
\hline Valve Lift [mm] & 3 \\
\hline Speed [RPM] & 1200 \\
\hline Intake Pressure $[\mathrm{kPa}]$ & 100 \\
\hline Intake Temperature $\left[{ }^{\circ} \mathrm{C}\right]$ & $75-132$ \\
\hline Fuel Pressure [bar] & 100 \\
\hline Injector Orifice Diameter $[\mu \mathrm{m}]$ & 125 \\
\hline Residual Gas Fraction [\%] & $\sim 45-47$ \\
\hline Exhaust Excess $\mathrm{O}_{2}[\%]$ & 2.4 \\
\hline Exhaust Temperature $\left[{ }^{\circ} \mathrm{C}\right]$ & $345-379$ \\
\hline Total Inj. Fuel Energy (main+NVO) [J/cycle] & $350-600$ \\
\hline $\mathrm{SOI}\left[\mathrm{CA}_{\mathrm{NVO}}\right]$ & -65 \\
\hline NVO Inj. Fuel Energy [J/cycle] & 265 \\
\hline NVO Bulk-Averaged Equiv. Ratio & $\sim 3.0$ \\
\hline $\mathrm{SOI}_{\mathrm{MAIN}}[\mathrm{CA}]$ & -270 \\
\hline
\end{tabular}

The operating conditions replicated low-load engine operation where combustion stability can be problematic. The engine speed was maintained at 1200 RPM via a motoring dynamometer with the intake air pressure fixed at $100 \mathrm{kPa}$ to mimic unthrottled naturally-aspirated operation. As LTGC engines normally feature compression ratios around 14:1, intake heating was used to artificially raise charge temperatures to compensate for the lower compression ratio of the engine used in the experiments. 


\subsubsection{Main-period engine performance}

To evaluate the impact of the NVO reformate stream on main-cycle combustion behavior, a custom 9-1 alternate-fire sequence with 1000 total cycles (i.e. 100 cycles-of-interest) was employed. The alternate-fire sequence featured 9 pre-conditioning cycles with main and NVO injections at a fixed total fueling rate of $604 \mathrm{~J} /$ cycle on a Lower Heating Value (LHV) basis. For the pre-conditioning cycles, the main start-of-injection $(\mathrm{SOI})$ timing was $\mathrm{SOI}_{\mathrm{MAIN}}=-270 \mathrm{CA}$ with the $\mathrm{NVO}$ injection at $\mathrm{SOI}=-45$

$\mathrm{CA}_{\mathrm{NVO}}$ (where $\mathrm{CA}$ is relative to main-period TDC and $\mathrm{CA}_{\mathrm{NVO}}$ is relative to $\mathrm{TDC}_{\mathrm{NVO}}$ ). The $9^{\text {th }}$ preconditioning cycle was followed by a cycle-of-interest with a NVO injection quantity of $265 \mathrm{~J} /$ cycle and $\mathrm{SOI}=-65 \mathrm{CA}_{\mathrm{NVO}}$ to generate the longest possible residence time for the relatively slow reforming reactions. The cycle-of-interest main-period injected fuel quantity was swept ( $85-335 \mathrm{~J} / \mathrm{cycle})$ such that the total cycle fuel energy varied between 350 and $600 \mathrm{~J} / c y c l e$. The alternate-fire sequence was designed to ensure that a common EVC temperature and composition were generated for the start of the cycle-of-interest NVO period across the main-period injected fuel quantity sweeps.

Four single-component gasoline surrogate fuels were studied: iso-octane, n-heptane, ethanol, and 1hexene. Single-component fuels were chosen because NVO samples from the engine fueled by a research gasoline were previously observed to be too complex for analysis by the PIMS diagnostic due to the large number of fuel constituents and associated intermediates [17]. Fuel and injection properties for the fuels tested in this study are presented in Table 2. Cyclohexane and the blend of toluene/nheptane $(81.1 \%$ toluene, $18.9 \%$ n-heptane by liquid volume; dictated by the experiment combustion stability requirements) were not studied in the main-period engine performance experiments, but the NVO reformates for these fuels were examined using the PIMS diagnostic.

Table 2. Fuel properties, injection parameters, and cycle temperatures. 


\begin{tabular}{|c|c|c|c|c|c|c|}
\hline & 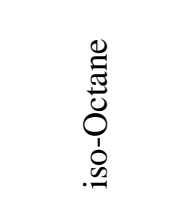 & 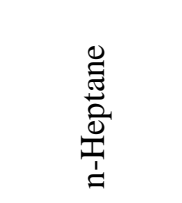 & $\begin{array}{l}\overline{0} \\
\text { 志 } \\
\text { 志 }\end{array}$ & 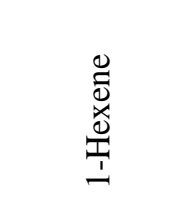 & 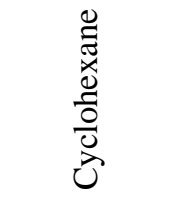 & 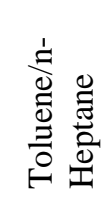 \\
\hline Liquid Density $\left[\mathrm{kg} / \mathrm{m}^{3}\right]^{\dagger}$ & 690 & 684 & 789 & 673 & 779 & 832 \\
\hline $\mathrm{LHV}[\mathrm{MJ} / \mathrm{kg}]^{\dagger \dagger}$ & 44.4 & 44.6 & 26.9 & 44.4 & 43.5 & 41.2 \\
\hline Heat of Vaporization $[\mathrm{kJ} / \mathrm{kg}]^{\dagger}$ & 302.5 & 317.2 & 850.2 & $363.9[18]$ & 356.7 & 354.7 \\
\hline Boiling Point $\left[{ }^{\circ} \mathrm{C}\right]^{\dagger}$ & 125.2 & 97.9 & 78.1 & $63.4[18]$ & 80.3 & 106.2 \\
\hline RON & 100 & 0 & $108[19]$ & $76.5[20]$ & $82.5[19]$ & $92.5^{\star}$ \\
\hline Sensitivity & 0 & 0 & $15.1[19]$ & $13.1[20]$ & $5.3[19]$ & $11.8^{\ddagger}$ \\
\hline \multicolumn{7}{|l|}{ Pre-conditioning Cycle Fueling (604 J/cycle) } \\
\hline NVO [mg/cycle] & 8.24 & 5.46 & 12.49 & 5.86 & 3.82 & 5.96 \\
\hline Main [mg/cycle] & 5.37 & 8.07 & 9.89 & 7.77 & 10.0 & 8.68 \\
\hline \multicolumn{7}{|l|}{ Cycle-of-Interest Fueling } \\
\hline NVO [mg/cycle] $(265 \mathrm{~J} /$ cycle $)$ & 5.97 & 5.95 & 9.83 & 5.98 & 6.10 & 6.44 \\
\hline Main [mg/cycle] $(85-335 \mathrm{~J} /$ cycle $)$ & $1.91-7.54$ & $1.91-7.52$ & $3.16-12.47$ & $1.91-7.54$ & N/A ${ }^{*}$ & N/A ${ }^{*}$ \\
\hline Intake Temp. $\left[{ }^{\circ} \mathrm{C}\right]$ & 132 & 75 & 132 & 90 & 91 & 132 \\
\hline Pre-conditioning Cycle Exhaust Temp. $\left[{ }^{\circ} \mathrm{C}\right]$ & 364 & 345 & 360 & 352 & 344 & 379 \\
\hline $\begin{array}{l}\text { Cycle-of-Interest IVC Temp. }\left[{ }^{\circ} \mathrm{C}\right](\text { Main Inj. }=335 \\
\mathrm{J} / \text { cycle })\end{array}$ & 217 & 193 & 201 & 212 & N/A* & N/A* \\
\hline \multicolumn{7}{|l|}{$\begin{array}{l}{ }^{\dagger} \text { Estimated using REFPROP [21] } \\
{ }_{\dagger}^{\dagger} \text { Estimated using CANTERA [22] } \\
{ }^{\dagger} \text { Estimated using the method of Ghosh et al. [19] } \\
{ }^{*} \text { Fuel only used for dump-sampling experiments. }\end{array}$} \\
\hline \multicolumn{7}{|c|}{ The intake temperature and pre-conditioning cycle $\mathrm{NVO} /$ main fuel injection split were adjusted for } \\
\hline \multicolumn{7}{|c|}{ each fuel to maintain stable main-period combustion (the coefficient-of-variation of cycle indicated } \\
\hline \multicolumn{7}{|c|}{ mean effective pressure (CoV of IMEP) for the preconditioning cycles was less than 0.03 ) with } \\
\hline \multicolumn{7}{|c|}{ ensemble-averaged exhaust temperatures between $345-379^{\circ} \mathrm{C}$ (see Table 2 ). Total fueling was } \\
\hline \multicolumn{7}{|c|}{ monitored by a Max Machinery Model 213 volumetric flow meter, with the NVO/main split set using a } \\
\hline \multicolumn{7}{|c|}{ predefined calibration map. Calibration values were $\pm 1 \%$ of the target total fueling rate, with NVO and } \\
\hline \multicolumn{7}{|c|}{ main injection commands proportionally adjusted to achieve the desired total fueling rates. There was an } \\
\hline \multicolumn{7}{|c|}{ unavoidable spread in exhaust temperatures among the fuels tested due to differences in the intake } \\
\hline \multicolumn{7}{|c|}{ temperature required to both avoid knock for the low-octane fuels and maintain stable combustion for } \\
\hline \multicolumn{7}{|c|}{ the high-octane fuels. To the extent possible, variations in exhaust temperature were compensated for } \\
\hline
\end{tabular}


The exhaust $\mathrm{O}_{2}$ concentration of the pre-conditioning cycles was adjusted to $\sim 2.4 \%$ (by mole) using a combination of nitrogen-diluted intake air ( $16 \%$ intake $\mathrm{O}_{2}$ by mole) and total fueling - the cycle-ofinterest NVO-period bulk-averaged equivalence ratios $(\varphi)$ were $\varphi \approx 3$. The exhaust $\mathrm{O}_{2}$ concentration, which dictates the $\mathrm{EVC} \mathrm{O}_{2}$ concentration for the cycle-of-interest, influences the balance between exothermic oxidation and reformation of fuel injected during the $\mathrm{NVO}$ period, with lower exhaust $\mathrm{O}_{2}$ concentration suppressing oxidation and promoting reformation [9-11].

\subsubsection{Dump-sample collection}

Gas sampling of the cycle-of-interest NVO reformate was conducted separately from the mainperiod engine performance measurements using a custom dump valve apparatus housed in a body that fit into an available $14 \mathrm{~mm}$ spark plug port. The sampling system consisted of a manifold connected to a vacuum evacuated, 1-liter, Teflon-lined, stainless-steel sample bottle as illustrated in Fig. 1. Solenoidoperated isolation and vacuum valves were used to minimize gas contamination from subsequent dump cycles or from engine blow-by across the dump-valve. All sampling system components were insulated and electrically heated to $90^{\circ} \mathrm{C}$ to avoid water and hydrocarbon condensation. For more sampling system details, the reader is referred to Steeper and Davisson [7].

The dump-cycle sequence in Fig. 2 was used to perform all sampling experiments. First, the engine was operated continuously using the same pre-conditioning cycles as the main-period engine performance measurements. Once measured cylinder head temperatures were steady, the dump-cycle sequence illustrated in Fig. 2 was activated. The single dump-cycle featured the same custom NVO injection as the cycle-of-interest in the main-period performance measurements $\left(\mathrm{SOI}=-65 \mathrm{CA}_{\mathrm{NVO}}\right.$; $265 \mathrm{~J} /$ cycle), no main injection, and actuation of the dump-valve system shortly after IVO (-200 CAD to $50 \mathrm{CAD}$ ) before concluding with continuous motored cycles. Accordingly, the dump cycle collected a mix of the cycle-of-interest end-period NVO reformate and intake charge. Dump sampling was repeated until the sample bottle pressure reached atmospheric pressure ( 7 dump samples). The engine was then stopped with the sample bottle isolated. 
Samples were transported to the Advanced Light Source (ALS) at the Lawrence Berkeley National Laboratory (LBNL) to be analyzed using a flame-sampling apparatus located at the Chemical Dynamics beamline (9.0.2). Every effort was made to minimize the time between sample collection at Sandia and sample characterization at the ALS, with the largest time lag between sample generation and characterization $\sim 8$ hours. It is important to note that even for fresh samples, there was no chance to retain and identify short-lived radicals, which would likely have quenched during the NVO period expansion anyways. Previous experiments compared fresh (1-2 hours) to aged (24+ hours) samples and found no significant variation in speciation [17].

\subsection{PIMS Sampling Apparatus Description}

The sample bottle was electrically heated to $60^{\circ} \mathrm{C}$ to avoid potential hydrocarbon and water condensation and sample was slowly fed by a MKS 1179 flow controller $\left(1.0 \mathrm{~cm}^{3} / \mathrm{min}\right)$ into the ionization chamber of the flame sampling apparatus through a stainless steel sampling probe. Tunable synchrotron generated VUV light was used to continuously ionize the expanded gas in the extraction region of a high-resolution reflectron time-of-flight mass spectrometer. Ions were extracted into a flight tube at a $30 \mathrm{kHz}$ repetition rate, with mass spectra of up 230 atomic mass units detected on a microchannel plate (MCP) detector. An energy scan was performed across a range of relevant photon energies (8.5-12.025 electron volts).

By feeding sample directly into the ionization chamber, a flame chamber bypass valve was avoided that previously led to a large percentage $(90 \%+)$ of lost sample in earlier experiments [17]. This change improved the diagnostic signal-to-noise ratio (SNR) by an order of magnitude through: (1) the elimination of sample argon dilution originally used to lengthen run times, (2) a larger number of MCP sweeps over a greater range of photon energies, and (3) a reduction of mass discrimination biases from mass spectrometer focusing. 


\subsection{PIMS Signal Post-Processing}

For each energy scan, background noise was subtracted from the ion count signal, with wavelet filters applied for further noise reduction. Signal time-of-flight measurements were correlated to the ion mass by a predefined calibration, with the signal counts binned in unity mass-to-charge $(\mathrm{m} / \mathrm{z})$ units to maximize SNR and facilitate spectral analysis. Processed signal from each energy scan was then stitched together to form an energy scan image as a function of photon energy and $\mathrm{m} / \mathrm{z}$.

A custom algorithm was developed to determine species constituents from each energy scan image. The ion count $S$ for mass $i$, energy $j$, and species $k$ was related to the species mole fraction $\chi$ as:

$$
S_{i, j, k}=\chi_{k} \cdot \sigma_{i, j, k} \cdot D_{i, k} \cdot \Phi_{j} \cdot P D_{j}^{-1} \cdot S W_{j} \cdot C_{j}
$$

The photoionization cross-section (PICS), $\sigma$, accounts for photon energy dependent ionization probabilities and photo-dissociation processes that lead to the formation of smaller ion fragments. PICS libraries were compiled for 335 species (see Ekoto et al. [17] for a list of referenced libraries). For libraries missing data at higher photon energies, these values were estimated from linear extrapolation of lower energy values. Extrapolated libraries agreed well with calibration datasets, but nonetheless introduced additional uncertainty during post-processing. The mass discrimination factor, $D$, was used to correct for minor mass spectrometer focusing biases and the ion collection efficiency from the VUV beam to the extraction zone. The terms $\Phi$ and $P D$ are the ALS beam photon flux and corresponding photodetector efficiency for a photodiode used to monitor beam irradiance. Total MCP sweeps, $S W$, were fixed at $2^{20}$ for each photon energy. Finally, an instrument-dependent proportionality constant $C$ was determined from an analysis of an energy scan for a calibration gas described below. The total energy scan signal image was then the sum of signal contributions from each sample constituent (i.e. $\left.S_{i, j}=\sum_{k} S_{i, j, k}\right)$. To determine sample speciation, PICS libraries and measured calibration terms from Eq. 1 were used to create synthetic photoionization efficiency (PIE) curves for each $\mathrm{m} / \mathrm{z}$ value. Mass-tocharge dependent PIE curves were summed to create a synthetic energy scan image, with species concentrations iteratively adjusted until the synthetic image intensity closely matched that of the 
measured energy scan signal image. To facilitate post-processing and improve accuracy, select species PICS libraries were removed if it was determined that their presence was unlikely. The calculated RGF was used to correct for NVO-period sample dilution by the intake charge. Peterson et al. [13] confirmed that the sampling results were not significantly impacted by intake air scavenging.

An energy scan image is shown in the upper right-hand corner of Fig. 3 for a calibration sample gas that contained 100 ppm each of 17 different hydrocarbons (acetylene, ethylene, ethane, allene, propyne, propylene, cyclopropane, acetaldehyde, propane, isobutene, trans-2-pentene, benzene, 1-hexene, cyclohexane, toluene, ethylbenzene, and p-xylene), 500 ppm each of 4 different hydrocarbons (n-butane, n-pentane, n-heptane, and iso-octane), and $2 \%$ oxygen with a nitrogen balance. As an illustrative example, the measured PIMS signal for the calibration gas at $m / z=44$ is compared in Fig. 3 to the cumulative synthetic PIE curve along with the individual spectra components from acetaldehyde, propane, and fragments of n-pentane and n-butane. The agreement with the cumulative PIE curve was well-matched to the measured PIMS signal; agreement between the measured and synthetic values was equally good at all other $\mathrm{m} / \mathrm{z}$, with the measured concentrations matched in most cases to $\pm 10 \%$ of the certified values.

\section{Results and discussion}

To confirm that the final pre-conditioning cycle reproduced the desired main-period combustion behavior before the cycle-of-interest for the main-period performance testing, 100-cycle ensembleaveraged in-cylinder pressure and apparent heat release rate (AHRR) profiles are plotted in Fig. 4 for each of the 9 pre-conditioning cycles. For the alternate-fire sequence in Fig. 4, the cycle-of-interest had $400 \mathrm{~J} /$ cycle of total fuel injected (the NVO/main split was $265 / 135 \mathrm{~J}$ ) and $\mathrm{SOI}=-65 \mathrm{CA}_{\mathrm{NVO}}$. The low cycle-of-interest total fueling rate relative to the $604 \mathrm{~J} /$ cycle for the pre-conditioning cycles was selected for this example because it led to the largest perturbation in steady-state behavior. Results are compared to profiles generated for a "target" pre-conditioning cycle obtained when the engine was operated 
continuously using the pre-conditioning cycle injection commands (as was the case before dump-sample collection).

Cycle-of-interest peak cylinder pressure and total heat release were much lower than corresponding pre-conditioning cycle values, as expected given the lower fueling rate. When fueling rates returned to pre-conditioning values, main-period combustion was initially well advanced relative to the target cycle. Greater excess- $\mathrm{O}_{2}$ and a larger stream of unburned hydrocarbons and $\mathrm{CO}$ from the cycle-of-interest fed into the NVO period of the first pre-conditioning cycle. The net effect was increased NVO-period fuel oxidation relative to the target pre-conditioning cycle that warmed IVC charge temperatures and advanced main-period auto-ignition. Combustion phasing for the next pre-conditioning cycle retarded relative to the target cycle, likely due to slightly lower exhaust temperatures — and hence slower NVO period reactions - from the proceeding cycle as a result of a marginally higher expansion ratio and increased wall heat losses.

As observed in Fig. 4, combustion phasing continued to advance and retard with successive preconditioning cycles, with the oscillations converging towards the target-cycle. By the final $\left(9^{\text {th }}\right)$ preconditioning cycle, AHRR and cylinder pressure profiles were steady and similar to the target cycle. Similar behavior was observed for all other alternate-fire sequences. These results demonstrate that the 9-1 alternate-fire sequence was able to accurately reproduce the thermal and chemical boundary condition for the cycle-of-interest NVO period.

\subsection{Main-period engine performance}

Ensemble-averaged main-period in-cylinder pressure and AHRR profiles for the cycle-of-interest are plotted in Fig. 5 for iso-octane, n-heptane, ethanol, and 1-hexene with fixed NVO injected fuel energy $\left(\mathrm{SOI}=-65 \mathrm{CA}_{\mathrm{NVO}} ; 265 \mathrm{~J}\right)$ and total injected fuel energies of $400 \mathrm{~J}(\mathrm{NVO} / \mathrm{main}=265 / 135 \mathrm{~J})$ and $600 \mathrm{~J}$ $(\mathrm{NVO} /$ main $=265 / 335 \mathrm{~J})$. It can be seen in Fig. 5 that combustion phasing varied with fuel type and total injected fuel energy. Note that the intake temperature was varied between the fuels so that main-period combustion phasing for the cycle-of-interest was phased near TDC, with stable main-period combustion 
and avoidance of knock. As a result, the combustion phasing can only be fairly compared amongst the variation in main-period fueling rates for the same fuel; i.e., main-period combustion phasing cannot be fairly compared among the fuels.

Trends in main-period combustion behavior with varied main-period injection energy are more easily interpreted using standard performance metrics. Combustion performance metrics for the cycleof-interest are plotted in Fig. 6 for iso-octane, n-heptane, ethanol, and 1-hexene as a function of the total cycle-of-interest fueling rate $(350-600 \mathrm{~J})$ for a fixed NVO injection $\left(\mathrm{SOI}=-65 \mathrm{CA}_{\mathrm{NVO}} ; 265 \mathrm{~J}\right)$. The crank angle at which $10 \%$ of the apparent heat release (AHR) occurred (CA10) was used to describe the ignition timing. The CoV of IMEP was used as a proxy for combustion stability. Finally, cycle indicated thermal efficiency (ITE) included contributions from both the main and NVO periods. Due to relative uncertainty in the measured fuel flow rate of $\pm 0.2 \%$ and in the IMEP of $\pm 2 \%$, reported ITE values are accurate to within approximately \pm 0.6 percentage points.

The approximate reformate fraction corresponding to each injection strategy is indicated on the upper x-axis of Fig. 6 (this will be referenced in the modeling section). Because the NVO injection was held constant at $265 \mathrm{~J}$ over a sweep of main-fueling energy, the global $\varphi$ decreased as the main-fueling energy was reduced (i.e. the reformate fraction increased). Such a strategy meant that PIMS speciation only needed to be performed for a single NVO fueling rate.

As the main-period injected fuel energy was decreased, the CA10 advanced for iso-octane, ethanol, and 1-hexene. The CA10 advance with decreased fueling was strongest for iso-octane, followed by ethanol and 1-hexene. Conversely, the CA10 retarded for n-heptane as the main-period fueling was decreased. From a kinetic standpoint, it would be expected that lower total fueling rates, and hence leaner $\varphi$, would exhibit retarded main-period combustion. Instead, for a fixed NVO injection, the lower total fueling rates resulted in a slight CA10 advance (except for n-heptane). The advance in CA10 with decreased total injected fuel energy may be caused by: (1) increased charge reactivity from the reformate, (2) decreased charge cooling from the decreased main-period injection mass, and/or (3) 
higher charge specific heat ratios $(\gamma)$. These phenomena will be explored in detail in the modeling section.

Despite a $2-6$ CA difference in CA10 across the total injected fuel energy sweep, there was essentially no impact on engine combustion stability. Acceptable combustion stability - defined here as a $\mathrm{CoV}$ of IMEP less than 0.03 - was reached across the fuel energy sweep for all tested fuels except at the lowest fueling rate.

ITE was $\sim 30 \%$ for iso-octane and n-heptane for total injected fuel energies of $500-600 \mathrm{~J}$, but ITE fell as the total injected fuel energy was decreased below 500 J. Similarly, ITE for 1-hexene was 30\% at the highest fueling rate, but fell as the main-period fueling was decreased. Interestingly, the ITE for 1-hexene was greater than the other fuels at the lowest total injected fuel energy, which can be attributed to the improved combustion stability for 1-hexene at these conditions. Ethanol had a slightly lower ITE than the other fuels at the highest fueling rate $(\sim 27.5 \%)$, with ITE falling as main-period fueling was decreased. Ethanol exhibited the lowest ITE among the fuels across the main-period injected fuel energy sweep due in part to increased NVO-period heat losses from increased NVOperiod heat release [14] and overly-advanced combustion phasing compared to the other fuels. As main-period fueling was decreased for ethanol, NVO-period heat losses were larger relative to the total injected fuel energy and combustion phasing continued to advance, leading to the steepest drop in ITE among the fuels. Other factors that influenced ITE trends included changes in combustion duration, charge $\gamma$, and heat losses through changes in the IVC temperature (from changes in evaporative cooling). A discussion of the interplay between these factors leading to the ITE trends for each fuel is beyond the scope of this paper.

\subsection{PIMS measurement data}

Ensemble-averaged in-cylinder pressure and heat release rate (HRR) profiles during the NVO period for the cycle-of-interest (i.e. dump sample collection cycles) are shown in Fig. 7 for the four fuels used for main-period engine performance testing, as well as two additional fuels: cyclohexane and the 
toluene/n-heptane blend. The HRR was determined by correcting the apparent heat release rate with the computed heat loss using a modified Woschni model following Wolk et al. [12]. All fuels, with the exception of ethanol, had little discernable heat release - a finding consistent with previous work [14].

Due to the low amount of available oxygen, the heat release was extended over much of the NVO period (from about -385 CA to $345 \mathrm{CA}$ ). The exothermic heat release present for the ethanol case ( 60 J) led to the highest peak bulk-averaged in-cylinder temperature $\left(T_{\text {peak }}\right)$ among the fuels (see Table 3). Similarly, the toluene/n-heptane mixture had a higher EVC temperature that led to the next highest $T_{\text {peak }}$.

The lack of significant heat release evidenced by in-cylinder pressure measurements for most fuels obscured the fact that the injected fuel was mostly converted to reformed product species. Table 3 presents RGF-corrected primary reforming product mole fractions at IVO for the six tested fuels taken through dump sampling and PIMS analysis. The PIMS diagnostic was not used to measure $\mathrm{H}_{2}, \mathrm{CO}$, and $\mathrm{CH}_{4}$ due to the high ionization potential for these species coupled with the fact that most PICS hydrocarbon libraries did not extend beyond $\sim 12 \mathrm{eV}$. Instead, GC-measured values obtained by Wolk et al. [14] at the same operating condition are reported in Table 3 and were used for reactor modeling. A complete table of product mole fractions for the 86 PIMS-measured species (compared to 27 with GC [14]) is given as Table A.1 in the Appendix.

Table 3. NVO reforming product mole fractions (in ppm) at IVO

\begin{tabular}{|c|c|c|c|c|c|c|c|c|}
\hline & $\begin{array}{l}0 \\
\text { जٓञँّ } \\
0 \\
\vdots \\
0 \\
0\end{array}$ & 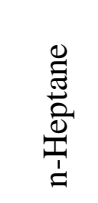 & $\begin{array}{l}\overline{0} \\
\text { ज्ञ } \\
\text { 壱 }\end{array}$ & 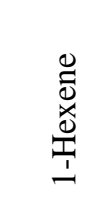 & 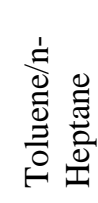 & 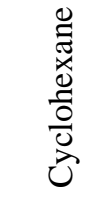 & 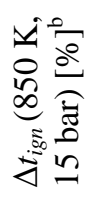 & 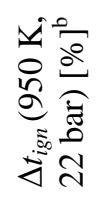 \\
\hline Exhaust $\mathrm{O}_{2}$ Conc. [\%] & 2.11 & 1.98 & 2.31 & 2.48 & 2.47 & 2.58 & & \\
\hline$\phi[-]$ & 3.87 & 4.00 & 3.06 & 3.07 & 3.07 & 2.74 & & \\
\hline RGF [\%] & 45.5 & 45.5 & 47.6 & 46.5 & 44.7 & 46.4 & & \\
\hline NVO-Period HR [J] & 3.3 & 9.4 & 58.7 & 21.6 & 16.1 & 17.7 & & \\
\hline$T_{\text {peak }}[\mathrm{K}]$ & 1095 & 1064 & 1246 & 1143 & 1235 & 1115 & & \\
\hline Fuel & 2202 & 1967 & 3079 & 934 & 3828 & 2106 & - & - \\
\hline Hydrogen $\left(\mathrm{H}_{2}\right)^{\mathrm{a}}$ & 4118 & 4120 & 11078 & 3680 & 2726 & 5275 & 0.8 & 0.0 \\
\hline Carbon monoxide $(\mathrm{CO})^{\mathrm{a}}$ & 8616 & 7705 & 17341 & 13414 & 9930 & 13171 & 0.3 & 0.1 \\
\hline Methane $\left(\mathrm{CH}_{4}\right)^{\mathrm{a}}$ & 4180 & 2144 & 4543 & 3173 & 1069 & 1897 & 1.1 & 0.9 \\
\hline Formaldehyde $\left(\mathrm{CH}_{2} \mathrm{O}\right)$ & 675 & 171 & 180 & 185 & 150 & 225 & 0.6 & -6.0 \\
\hline
\end{tabular}




\begin{tabular}{|c|c|c|c|c|c|c|c|c|}
\hline Acetylene $\left(\mathrm{C}_{2} \mathrm{H}_{2}\right)$ & 832 & 768 & 803 & 1475 & 1365 & 1566 & -15.7 & -12.6 \\
\hline Ethylene $\left(\mathrm{C}_{2} \mathrm{H}_{4}\right)$ & 1248 & 3610 & 1611 & 3561 & 984 & 4831 & 0.3 & -0.3 \\
\hline Acetaldehyde $\left(\mathrm{CH}_{3} \mathrm{CHO}\right)$ & 85 & 126 & 661 & 165 & 31 & 276 & -12.4 & -7.3 \\
\hline Ethane $\left(\mathrm{C}_{2} \mathrm{H}_{6}\right)$ & 0 & 101 & 233 & 0 & 96 & 53 & 4.2 & 1.1 \\
\hline Allene $\left(\mathrm{C}_{3} \mathrm{H}_{4}-\mathrm{A}\right)$ & 163 & 0 & 0 & 5 & 22 & 1 & -7.9 & -9.6 \\
\hline Propyne $\left(\mathrm{C}_{3} \mathrm{H}_{4}-\mathrm{P}\right)$ & 225 & 27 & 11 & 82 & 42 & 64 & -1.7 & 0.1 \\
\hline Vinyl-acetylene $\left(\mathrm{C}_{4} \mathrm{H}_{4}\right)$ & 23 & 9 & 0 & 33 & 52 & 37 & -21.3 & -18.5 \\
\hline Propene $\left(\mathrm{C}_{3} \mathrm{H}_{6}\right)$ & 967 & 562 & 45 & 669 & 87 & 340 & -2.2 & -1.7 \\
\hline Propane $\left(\mathrm{C}_{3} \mathrm{H}_{8}\right)$ & 33 & 67 & 8 & 25 & 8 & 44 & 4.2 & 0.4 \\
\hline 2-Methyl-1-butene $\left(\mathrm{A}-\mathrm{C}_{5} \mathrm{H}_{10}\right)$ & 0 & 70 & 0 & 26 & 2 & 32 & -11.5 & -7.2 \\
\hline 3-Methyl-1-butene $\left(\mathrm{C}-\mathrm{C}_{5} \mathrm{H}_{10}\right)$ & 3 & 55 & 0 & 0 & 20 & 87 & -15.7 & -10.6 \\
\hline Benzene $\left(\mathrm{C}_{6} \mathrm{H}_{6}\right)$ & 96 & 16 & 4 & 108 & 755 & 244 & 0.3 & -0.3 \\
\hline Phenol $\left(\mathrm{C}_{6} \mathrm{H}_{5} \mathrm{OH}\right)$ & 0 & 0 & 0 & 0 & 76 & 0 & -9.8 & -5.3 \\
\hline 1,3-Hexadiene $\left(\mathrm{C}_{6} \mathrm{H}_{10} 1-3\right)$ & 18 & 0 & 0 & 2 & 0 & 0 & -8.7 & -5.4 \\
\hline 1,5-Hexadiene $\left(\mathrm{C}_{6} \mathrm{H}_{10} 1-5\right)$ & 12 & 0 & 0 & 15 & 3 & 42 & -5.1 & -5.6 \\
\hline Benzaldehyde $\left(\mathrm{C}_{6} \mathrm{H}_{5} \mathrm{CHO}\right)$ & 0 & 0 & 0 & 0 & 13 & 0 & -31.7 & -20.3 \\
\hline
\end{tabular}

The two rightmost columns in Table 3 quantify the impact of the individual species on reformate reactivity through ignition delay ( $t_{\text {ign }}$; constant volume) modeling. The metric presented $\left(\Delta t_{i g n}(T, P)\right)$ is the difference in $t_{i g n}$ between neat PRF60 (60\% iso-octane, 40\% n-heptane by liquid volume) and the $t_{\text {ign }}$ of $95 \%$ PRF60 $+5 \%$ by mole of a test species from Table 3 (e.g. acetylene) at stoichiometric conditions. PRF60 was chosen as a representative fuel following the well-established method for evaluating liquid fuel blending octane numbers [16]. The $t_{i g n}$ calculations were performed in CHEMKIN-PRO [23] using the detailed LLNL gasoline surrogate mechanism [23] at temperatures and pressures representative of $20 \mathrm{CA}(850 \mathrm{~K}, 15$ bar; just before the start of heat release) and main-period TDC (950 K, 22 bar), as determined from experimental measurements. The oxidizer stream was taken as a weighted-average of the GC-measured iso-octane and n-heptane oxidizer streams from [14]: 8.89\% $\mathrm{O}_{2}, 4.53 \% \mathrm{CO}_{2}, 5.12 \%$ $\mathrm{H}_{2} \mathrm{O}$ (estimated from the measured $\mathrm{CO}_{2}$ using the fuel $\mathrm{H} / \mathrm{C}$ ratio), and $81.46 \% \mathrm{~N}_{2}$ (balance). The test species molar fuel fraction in the $t_{i g n}$ calculations was selected to be $5 \%$ ( 400 ppm by mole of the overall fuel/oxidizer mixture concentration) because $t_{i g n}$ was found to linearly vary with the test species concentration up to this threshold for acetylene and acetaldehyde. 
A negative value of $\Delta t_{i g n}(T, P)$ indicates that the test species decreased $t_{i g n}$, and hence increased the total fuel reactivity, at the indicated temperature and pressure, and vice versa. The computed $\Delta t_{i g n}(T, P)$ in Table 3 show that acetylene, acetaldehyde, allene, vinylacetylene, propene, 2-methyl-1-butene, 3methyl-1-butene, 1,3-hexadiene, 1,5-hexadiene, benzaldehyde, and formaldehyde can significantly increase mixture reactivity at the given concentration. The actual impact on reactivity depends on both the relative impact described by $\Delta t_{i g n}(T, P)$ and the measured species concentration. Considering these two factors, acetylene is determined to be the most important species for increasing reactivity for all fuels tested; small concentrations of acetylene have been previously observed to significantly increase mixture reactivity [7]. The analysis also indicates that acetaldehyde is important for increasing reactivity, especially for ethanol and to a lesser extent cyclohexane. Additionally, the analysis suggests that propene is important for increasing reactivity for iso-octane, n-heptane, 1-hexene, and cyclohexane while allene has an important impact on reactivity for iso-octane only. Vinyl-acetylene is very efficient at improving reactivity, but was only measured in appreciable amounts for iso-octane, 1-hexene, toluene/n-heptane, and cyclohexane. Interestingly, the analysis suggests that formaldehyde leads to improved reactivity for all fuels only at the higher temperature condition ( $950 \mathrm{~K})$. It should be noted that methane, hydrogen, and carbon monoxide are present in large concentrations and act to reduce reactivity.

\subsubsection{Comparison of PIMS and GC}

With an understanding of which PIMS-measured species are the most important contributors to increased mixture reactivity, the shortcomings of GC in characterizing reformates for LTGC is apparent. Figure 8 compares $\mathrm{C}_{2}, \mathrm{C}_{3}$ and $\mathrm{C}_{4}$ hydrocarbon mole fractions measured using the PIMS technique to the GC analysis published previously by the authors [14] for the same engine operating conditions. The total concentrations in Fig. 8 are in good agreement given the fact that the PIMS and GC samples were collected on different days. More importantly, the advantages of the PIMS diagnostic are clear as more compounds in a similar molecular weight range, including isomers, could be identified than could be 
achieved through chromatography. Additionally, PIMS can discern between acetylene/ethylene as well as propyne/allene whereas the GC column used in [14] could not (acetylene and ethylene could be separated by using a slower-eluting column than [14]). Acetylene has arguably the most significant impact on mixture reactivity while ethylene has almost no impact, so accurate determination of the acetylene/ethylene ratio is essential. Similarly, allene more efficiently increases mixture reactivity relative to propyne, so quantification of these isomers is critical. The increased speciation detail for higher hydrocarbon classes with PIMS also led to identification of important reactivity-increasing reformate species absent from GC, namely vinyl-acetylene.

\subsection{Reactor modeling}

To evaluate the reformate reactivity for each fuel compared to the unreformed parent fuel, $t_{i g n}$ was computed for mixtures of the parent fuel and the PIMS-measured reformate stream (minus any parent fuel components). Computations were conducted at $\varphi=1.0$ using temperatures and pressures representative of $-20 \mathrm{CA}(850 \mathrm{~K}, 15 \mathrm{bar})$ and TDC $(950 \mathrm{~K}, 22 \mathrm{bar})$ during the main period, and the GC-

measured oxidizer stream for each fuel $\left(\sim 9 \% \mathrm{O}_{2}, \sim 4 \% \mathrm{CO}_{2}, \sim 5 \% \mathrm{H}_{2} \mathrm{O}, \sim 82 \% \mathrm{~N}_{2}\right)$ [14]. The $t_{\text {ign }}$ were computed using the LLNL gasoline surrogate detailed mechanism [23], except in the case of cyclohexane for which the LLNL cyclohexane detailed mechanism [24] was used. The computed $t_{i g n}$ as a function of mass fraction of reformate in the unreformed parent fuel and reformate blend are presented in Fig. 9 ( 1 = reformate only, $0=$ parent fuel only $)$.

Focusing first on the $850 \mathrm{~K}$ condition in Fig. 9a, it is observed that iso-octane, toluene/n-heptane, and cyclohexane have monotonically increasing reactivity as the reformate fraction increases (right to left). Conversely, n-heptane and 1-hexene have nearly constant reactivity until the reformate fraction exceeds $\sim 80-90 \%$, at which point reactivity decreases. Reactivity decreases for n-heptane and 1-hexene because the neat reformate is less reactive than the unreformed parent fuel.

Ethanol is unique in that it has a rapid increase in reactivity for low reformate fractions (up to $\sim 10 \%$ ), which may be caused by the large acetaldehyde concentrations relative to the other fuels. The 
cyclohexane reformate has about $40 \%$ of the acetaldehyde concentration of the ethanol reformate and similarly shows a steeper slope at very low reformate fractions $(<10 \%)$. Additionally, ethanol exhibits increased reactivity for intermediate reformate mass fractions beyond the reactivity of the neat reformate. No other fuel tested exhibits such a strong non-monotonic behavior of reactivity with reformate fraction; the closest counterpart is 1-hexene, which has slightly increased reactivity up to $\sim 70 \%$ reformate fraction before ultimately decreasing.

At the higher temperature examined (950 K; Fig. 9b), the trends in $t_{\text {ign }}$ are consistent with the lower temperature $(850 \mathrm{~K})$ for all fuels except n-heptane. At $950 \mathrm{~K}$, increasing the $\mathrm{n}$-heptane reformate fraction steadily increases reactivity. This is caused by n-heptane exiting the negative temperature coefficient (NTC) region for the higher temperature. The reformate does not exhibit any NTC behavior, so the reactivity advantage of n-heptane is diminished at temperatures above the NTC region.

Modeling results for the fuels in Fig. 9 indicate that increasing the reformate fraction increases reactivity for stoichiometric global $\varphi$. However, decreased main-period fueling at a fixed NVO injection energy in the current experiments led to an increased reformate fraction of total fueling but decreased global $\varphi$. It is important to note that altered main-period fueling rates influenced reactivity in the experiments though multiple effects: (1) the reformate fraction of total fueling, (2) the bulk-averaged compressed temperature, which was influenced by the IVC temperature and the charge $\gamma$, and (3) the global $\varphi$.

PIMS-measured sampling results, main-period fuel injection quantities, and measured in-cylinder pressures for the cycle-of-interest were used to estimate the charge $\gamma$ during compression along with the bulk-averaged temperature at -20 CA across the sweep of total injected fuel energy; results for isooctane, n-heptane, ethanol, and 1-hexene are plotted in Fig. 10. The charge $\gamma$ during compression was determined from the slope of the logarithm of in-cylinder pressure versus the logarithm of volume from $-130 \mathrm{CA}$ to $-20 \mathrm{CA}$. As the total injected fuel energy was reduced, the $\gamma$ increased for all fuels. 1-Hexene exhibited the largest increase in $\gamma$ across the main-period injected fuel energy sweep due to having 
relatively high concentrations of light hydrocarbon species (i.e. a higher $\gamma$ of the reformate). The increases in $\gamma$ are similar among iso-octane, $\mathrm{n}$-heptane, and ethanol. The magnitude of the charge $\gamma$ for each fuel is impacted by the IVC temperature as well the parent fuel $\gamma$.

The bulk-averaged temperature at -20 CA increased as the main-period injected fuel energy was decreased due to the increased $\gamma$ and higher IVC temperature from decreased evaporative charge cooling. Iso-octane and n-heptane show similar increases in temperature at -20 CA due to similar latent heats of vaporization and similar behavior of $\gamma$ across the range of main-period fueling. Ethanol has a similar behavior of $\gamma$ compared to iso-octane and n-heptane, but has a much higher latent heat of vaporization. As a result, the greater decrease in evaporative cooling as main-period fueling was reduced for ethanol led to a larger increase in temperature at -20 CA. Differently, 1-hexene has a similar latent heat of vaporization compared to iso-octane and n-heptane, but had a greater increase in $\gamma$ for reduced main-period fueling. As a result, the increase in temperature at -20 CA across the main-period fueling sweep was greater for 1-hexene than either iso-octane or n-heptane.

As the main-period injected fuel energy was reduced, the increased bulk-averaged temperature at -20 CA coupled with the increased reformate fraction acted to increase reactivity. These reactivity gains were simultaneously offset by the decreased global $\varphi$. To determine the driving factor behind the measured CA10 change with decreased main-period fueling at a fixed NVO injection quantity for each fuel, representative $t_{i g n}$ calculations were performed at 15 bar initial pressure (constant volume). Note that the isochoric $t_{i g n}$ calculations do not account for the dynamic nature of the compression that would result in moderate changes to pressure/temperature.

Figure 11 presents simulated $t_{\text {ign }}$ values for iso-octane, n-heptane, ethanol, and 1-hexene mixed with their respective PIMS-measured reformate streams at representative bulk-gas temperatures from Fig. 10. The solid lines for each fuel in Fig. 11 were calculated using the reformate fraction of the $600 \mathrm{~J}$ case ( $\sim 36 \%$ reformate, $\sim 64 \%$ parent fuel by mass) at $\varphi$ matching the $600 \mathrm{~J}$ and $400 \mathrm{~J}$ cases with the GCmeasured oxidizer stream ( $\sim 9 \% \mathrm{O}_{2}, \sim 4 \% \mathrm{CO}_{2}, \sim 5 \% \mathrm{H}_{2} \mathrm{O}, \sim 82 \% \mathrm{~N}_{2}$ by mole) [14]. The dashed line for 
each fuel in Fig. 11 uses the actual reformate fraction ( $~ 59 \%$ reformate, $\sim 41 \%$ parent fuel by mass) and $\varphi$ for the $400 \mathrm{~J}$ case. The change in $t_{i g n}$ as $\varphi$ decreases at constant reformate fraction with the corresponding increase in temperature from Fig. 10 is highlighted in Fig. 11 (from the circle marker on $600 \mathrm{~J}$ line to the circle marker on the $400 \mathrm{~J}$ line). Additionally, the impact of increased reformate fraction for the $400 \mathrm{~J}$ case is indicated in Fig. 11 by the diamond marker relative to the circle marker.

Looking first at the constant reformate fraction (solid) lines for iso-octane, the calculated $t_{\text {ign }}$ increases as $\varphi$ decreases from the $600 \mathrm{~J}$ to $400 \mathrm{~J}$ lines at fixed initial temperature (as would be expected). When the initial temperature increases to the higher compressed temperature for the $400 \mathrm{~J}$ case (Fig. 10), only part of the difference in $t_{i g n}$ is recovered. This indicates that the increase in compressed temperature for lower main-period injected fuel energy was insufficient by itself to overcome the decrease in reactivity with lower $\varphi$. The dashed lines in Fig. 11 include the impact of the increased reformate fraction at lower main-period injected fuel energy. Because increasing reformate fraction increases the charge reactivity for iso-octane in the reformate fraction range considered (Fig. 9), the $t_{\text {ign }}$ is reduced further (diamond marker compared to circle marker for $400 \mathrm{~J}$ ). For the $400 \mathrm{~J}$ case, the increased compressed temperature and increased reactivity from the higher reformate fraction offset the decrease in reactivity from the lower $\varphi$ compared to the $600 \mathrm{~J}$ case. However, the computed $t_{\text {ign }}$ for the $400 \mathrm{~J}$ case (diamond marker) is larger than the $600 \mathrm{~J}$ baseline (circle marker on $600 \mathrm{~J}$ line), which is contrary to the CA10 trends in Fig. 6. The lack of absolute agreement between the $t_{i g n}$ and CA10 trends may be caused by uncertainty in the estimated temperature at -20 CA across the sweep of total injected fuel energy. Despite these shortcomings, the modeling results suggest that the reactivity improvement from increased reformate fraction for iso-octane played an important role in the measured CA10 advance.

Different from iso-octane, there is no improvement in reactivity for n-heptane from the increased reformate fraction at the $400 \mathrm{~J}$ condition. This is evident from the near-colocation of the circle and diamond markers on the $400 \mathrm{~J}$ lines for $\mathrm{n}$-heptane in Fig. 11 as well as the insensitivity of $t_{\text {ign }}$ to reformate fraction in Fig. 9 (in the range considered, $\sim 36 \%$ to $\sim 59 \%$ reformate by mass in $n-$ 
heptane/reformate blend). Therefore, the retard in CA10 for n-heptane was due to the increased compressed temperature at lower main-period injected fuel energy being insufficient to overcome the decrease in reactivity from the lower $\varphi$.

Ethanol also exhibits negligible change in reactivity from the increased reformate fraction at the 400 $\mathrm{J}$ condition. However, the increase in compressed temperature for ethanol at lower main-period injected fuel energy was sufficient to overcome the decrease in reactivity from lower $\varphi$. This indicates that the measured CA10 advance for ethanol was dictated by thermal effects. It is important to note that while ethanol is insensitive to reformate fraction in the range used in the current experiments ( $\sim 36 \%$ to $\sim 59 \%$ reformate by mass in ethanol/reformate blend), ethanol displayed sensitivity to changes in reformate fraction at lower reformate fractions (up to 20\%; see Fig. 9).

Similar to ethanol, 1-hexene has negligible change in reactivity from increased reformate fraction at the $400 \mathrm{~J}$ condition. While the increase in compressed temperature for 1-hexene at lower main-period injected fuel energy was not sufficient to decrease $t_{i g n}$ below the $600 \mathrm{~J}$ baseline (circle marker on $600 \mathrm{~J}$ line), it brought $t_{i g n}$ closer to the $600 \mathrm{~J}$ baseline than either iso-octane or $\mathrm{n}$-heptane. This indicates that the reactivity improvement from increased compressed temperature for 1-hexene played an important role in the measured CA10 advance. Different from ethanol, 1-hexene is relatively insensitive to changes in reformate fraction up to $\sim 90 \%$ reformate by mass (in 1-hexene/reformate blend; see Fig. 9).

Iso-octane had the strongest advance in CA10 with decreased main-period injected fuel energy compared to the other fuels tested (Fig. 6). This may be explained, in part, by the fact that iso-octane was the only fuel that experienced a chemical improvement in reactivity from the increased reformate fraction at decreased main-period injected fuel energy (within the reformate fraction range considered). Ethanol had the next strongest advance in CA10, which may be due to ethanol having the largest increase in compressed temperature across the main-period injected fuel energy sweep (Fig. 10); the increase in compressed temperature for ethanol was primarily caused by the decreased evaporative cooling for decreased main-period injection mass. 


\section{Conclusions}

In the current study, the impact of NVO reformate on main-period combustion performance was examined for four single-component surrogate gasoline fuels (iso-octane, n-heptane, ethanol, and 1hexene) using a custom alternate-fire sequence. Separately, gas sampling of the NVO reformate and PIMS detailed speciation were performed for the four tested fuels, as well as cyclohexane and a blend of toluene/n-heptane. All experiments were conducted in a direct-injected, single-cylinder, automotive research engine, with gas samples collected at the end of the NVO cycle using a custom dump-valve apparatus. An adiabatic, single-zone reactor model was used to evaluate the charge reactivity of the PIMS-measured reformates compared to the unreformed parent fuels and to examine the factors influencing main-period engine performance. Major study findings are summarized as follows:

- Acetylene is identified as having the largest impact on increasing reformate reactivity for all fuels tested due to its strong relative impact on reactivity and high concentration. The impact of other reformate species on reactivity mostly depended on fuel-specific species yields. For instance, acetaldehyde was important primarily for ethanol, allene was only important for isooctane, and propene was important for iso-octane, $\mathrm{n}$-heptane, 1-hexene, and cyclohexane.

- A main advantage of PIMS over the GC methods employed in this study was the ability to discern between species with similar elution times but drastically different effects on reactivity (e.g. acetylene/ethylene and allene/propyne).

- Single-zone reactor modeling indicates that iso-octane, toluene/n-heptane, and cyclohexane reactivity monotonically increase with an increased reformate fraction of total fueling while nheptane and 1-hexene have small reactivity variations, except at very high reformate fractions (> 80\%) where reactivity decreases. Different from the other fuels, ethanol exhibited sharp reactivity increases for low reformate fractions $(<10 \%)$. Additionally, the ethanol/reformate blends were more reactive than both the ethanol and ethanol reformate alone. 
- For constant NVO injection energy and decreasing main-period fueling, iso-octane had the strongest advance in measured CA10 among the fuels tested primarily due to the NVO reformate increasing reactivity. The measured CA10 advance for ethanol and 1-hexene was weaker than that of iso-octane and was primarily governed by increased compressed temperature rather than increased reactivity from the NVO reformate. Decreased evaporative charge cooling was largely responsible for the temperature increase for ethanol, while increased $\gamma$ was primarily responsible for the temperature increase for 1-hexene. The measured CA10 retard for n-heptane was a result of the increased compressed temperature being insufficient to offset reactivity decreases from the lower $\varphi$ for decreased main-period fueling.

The results presented in this paper demonstrate that NVO-generated reformate can improve mainperiod reactivity through both chemical and thermal effects, although significant NVO-period heat losses reduce total-cycle engine thermal efficiency. The results also underscore the importance of using accurate chemical mechanisms in engine models that faithfully represent the influence of reformate species on auto-ignition.

\section{Acknowledgements}

Some of the work presented in this paper was performed at the Combustion Research Facility, Sandia National Laboratories, Livermore, CA. Financial support was provided by the U.S. Department of Energy, Office of Vehicle Technologies. Sandia National Laboratories is a multi-program laboratory managed and operated by Sandia Corporation, a wholly owned subsidiary of Lockheed Martin Corporation, for the U.S. Department of Energy’s National Nuclear Security Administration under contract DE-AC04-94AL85000. The Advanced Light Source is supported by the Director, Office of Science, Office of Basic Energy Sciences, of the U.S. Department of Energy under Contract No. DE- 


\title{
AC02-05CH11231. The authors also gratefully acknowledge contributions from Marco Mehl of LLNL
}

\author{
and the engineering support provided by Alberto Garcia.
}

\section{References}

[1] S. Saxena, I. D. Bedoya, Prog Energ Combust 39 (5) (2013) 457-488.

[2] H. Machrafi, S. Cavadias, P. Gilbert, Fuel Process Technol 89 (11) (2008) 1007-1016.

[3] H. Yun, N. Wermuth, P. Najt, 4 (1) (2011) 1190-1201.

[4] G. A. Lavoie, J. Martz, M. Wooldridge, D. Assanis, Combust Flame 157 (6) (2010) 1106-1110.

[5] J. Kodavasal, G. A. Lavoie, D. N. Assanis, J. B. Martz, Combust Flame 162 (2) (2015) 451-461.

[6] J. E. Dec, Y. Yang, J. Dernotte, C. Ji, SAE Int J Engines 8 (3) (2015) 935-955.

[7] R. R. Steeper, M. L. Davisson, SAE Int J Engines 7 (2) (2014) 762-771.

[8] N. Wermuth, H. Yun, P. Najt, SAE Int J Engines 2 (1) (2009) 823-836.

[9] I. Ekoto, B. Peterson, J. Szybist, W. Northrop, SAE Int J Engines 8 (5) (2015).

[10] J. P. Szybist, R. R. Steeper, D. Splitter, V. B. Kalaskar, J. Pihl, C. Daw, SAE Int J Engines 7 (1) (2014) $418-433$.

[11] J. Hunicz, Fuel 117 (A) (2014) 236-250.

[12] T. Alger, B. Mangold, SAE Int J Engines 2 (1) (2009).

[13] B. Peterson, I. Ekoto, W. Northrop, SAE Int J Engines 8 (2) (2015) 747-757.

[14] B. Wolk, I. Ekoto, W. Northrop, 2016 SAE World Congress (Submitted).

[15] N. Hansen, J. A. Miller, P. R. Westmoreland, T. Kasper, K. Kohse-Hoinghaus, J. Wang, T. A. Cool, Combust Flame 156 (11) (2009) 2153-2164.

[16] R. P. Fitzgerald, R. Steeper, J. Snyder, R. Hanson, R. Hessel, SAE Int J Engines 3 (1) (2010) 124-141.

[17] I. Ekoto, S. Skeen, R. R. Steeper, N. Hansen, SAE Int J Engines 9 (1) (2015).

[18] D. L. Camin, F. D. Rossini, J Phys Chem-Us 60 (10) (1956) 1446-1451.

[19] P. Ghosh, K. J. Hickey, S. B. Jaffe, Ind Eng Chem Res 45 (1) (2006) 337-345.

[20] Physical Constants of Hydrocarbons and Non-Hydrocarbon Compounds, ASTM Data Series DS4B, 2nd Ed., 30:30ASTM, Philadelphia, PA, 1988.

[21] Lemmon EW, Huber ML, M. MO, NIST reference fluid thermodynamic and transport properties-REFPROP. Ed. 8, Gaithersburg, MD: U. S. Department of Commerce Technology Administration, National Institute of Standards and Technology, Standard Reference Data Program, April, 2007.

[22] D. G. Goodwin, H. K. Moffat, R. L. Speth, Cantera: An object- oriented software toolkit for chemical kinetics, thermodynamics, and transport processes. 2015.

[23] M. Mehl, W. J. Pitz, C. K. Westbrook, H. J. Curran, P Combust Inst 33 (2011) 193-200.

[24] E. J. Silke, W. J. Pitz, C. K. Westbrook, M. Ribaucour, J Phys Chem A 111 (19) (2007) 3761-3775. 


\section{List of Figure Captions}

Figure 1. Illustration of the custom dump valve system and 1-liter sample bottle.

Figure 2. Schematic illustrating the dump-sample collection sequence. First, the engine was operated using preconditioning cycles with main and NVO injections. Once cylinder head temperatures were steady, a single dumpcycle was activated with a custom NVO injection, no main injection, and actuation of the dump-valve system. After the single dump-cycle, the engine was motored. This process was then repeated ( 6-8 dump samples).

Figure 3. Measured PIMS signal for a 23-component calibration gas sample at $\mathrm{m} / \mathrm{z}=44$ compared to the cumulative PIE curve and individual synthetic spectra components for hydrocarbons with known $44 \mathrm{~m} / z$ ion fragments over the range of energy scan photon energies $(8.5-12.025 \mathrm{eV})$. The complete energy scan image is shown in the upper right-hand corner for reference.

Figure 4. Main-period ensemble-averaged cylinder pressure (top) and AHRR (bottom) profiles for a cycle-ofinterest $\left(\mathrm{SOI}=-65 \mathrm{CA}_{\mathrm{NVO}} ; 400 \mathrm{~J} / \mathrm{cycle}\right)$ along with each pre-conditioning cycle and target pre-conditioning cycle profiles.

Figure 5. Main-period ensemble-averaged cylinder pressure (top) and AHRR (bottom) profiles for iso-octane, nheptane, ethanol, and 1-hexene with a fixed NVO injection $\left(\mathrm{SOI}=-65 \mathrm{CA}_{\mathrm{NVO}} ; 265 \mathrm{~J}\right)$ at total cycle-of-interest fueling rates of $400 \mathrm{~J}$ and $600 \mathrm{~J}$.

Figure 6. Experimental main-period CA10 (average of 100 cycles-of-interest), CoV of IMEP, and ITE for a sweep of main-period fueling energy with a constant $265 \mathrm{~J}$ NVO injection. The approximate reformate mass fraction of the total fuel and reformate is indicated on the upper $\mathrm{x}$-axis.

Figure 7. In-cylinder pressure and heat release rate versus crank angle during the NVO period for all fuels tested.

Figure 8. Comparison of NVO reformate bulk speciation from GC analysis [12] versus the PIMS results for $\mathrm{C}_{2}$ (top), $\mathrm{C}_{3}$ (middle) and $\mathrm{C}_{4}$ (bottom) hydrocarbons.

Figure 9. $t_{i g n}$ for mixtures of reformate and parent fuel at (a) $850 \mathrm{~K}, 15$ bar and (b) $950 \mathrm{~K}, 22$ bar.

Figure 10. Estimated bulk-averaged temperature at -20 CA (solid lines, left y-axis) and charge $\gamma$ during compression (dashed lines, right y-axis) for iso-octane, n-heptane, ethanol and 1-hexene. Fixed NVO injection of $265 \mathrm{~J} /$ cycle with $\mathrm{SOI}=-65 \mathrm{CA}_{\mathrm{NVO}}$.

Figure 11. $t_{i g n}$ as a function of initial temperature at 15 bar for iso-octane, n-heptane, ethanol, and 1-hexene with $400 \mathrm{~J}$ and $600 \mathrm{~J}$ of total fuel energy using the PIMS-measured reformate and the GC-measured oxidizer stream $\left(9.5 \% \mathrm{O}_{2}, 4.8 \% \mathrm{CO}_{2}, 4.9 \% \mathrm{H}_{2} \mathrm{O}, 80.8 \% \mathrm{~N}_{2}\right)$. 


\section{Appendix}

Table A.1. Complete table of NVO reformate composition for six tested fuels as measured by PIMS (in ppm).

\begin{tabular}{|c|c|c|c|c|c|c|c|c|c|}
\hline & & 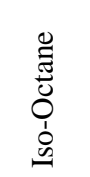 & 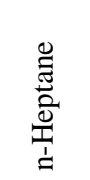 & $\begin{array}{l}\overrightarrow{0} \\
\text { 志 } \\
\text { 壱 }\end{array}$ & 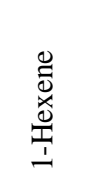 & 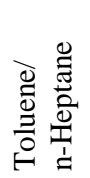 & 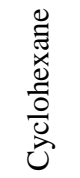 & & \\
\hline $\mathrm{EVC} \mathrm{O}_{2}$ & {$[\%]$} & 2.11 & 1.98 & 2.31 & 2.48 & 2.47 & 2.58 & & \\
\hline Exhaust Temperature & {$[\mathrm{K}]$} & 364 & 360 & 345 & 352 & 379 & 344 & & \\
\hline Residual Gas Fraction & {$[\%]$} & 45.5 & 45.5 & 47.6 & 46.5 & 44.7 & 46.4 & & \\
\hline NVO Global Bulk-Avg. Equiv. Ratio & {$[-]$} & 3.87 & 4.00 & 3.06 & 3.07 & 3.07 & 2.74 & & \\
\hline Species: Formula & & & & & & & & $\begin{array}{c}\Delta t_{\text {ign }}(850 \mathrm{~K}, \\
15 \text { bar })^{\mathrm{b}}\end{array}$ & $\begin{array}{c}\Delta t_{i g n}(950 \mathrm{~K}, \\
22 \text { bar })^{\mathrm{b}}\end{array}$ \\
\hline Acetylene: $\mathrm{CH} \equiv \mathrm{CH}$ & {$[\mathrm{ppm}]$} & 832 & 768 & 803 & 1475 & 1365 & 1566 & $-15.7 \%$ & $-12.6 \%$ \\
\hline Ethylene: $\mathrm{CH}_{2}=\mathrm{CH}_{2}$ & {$[\mathrm{ppm}]$} & 1248 & 3610 & 1611 & 3561 & 984 & 4831 & $0.3 \%$ & $-0.3 \%$ \\
\hline Ethane: $\mathrm{CH}_{3} \mathrm{CH}_{3}$ & {$[\mathrm{ppm}]$} & 0 & 101 & 233 & 0 & 96 & 53 & $4.2 \%$ & $1.1 \%$ \\
\hline Formaldehyde: $\mathrm{H}_{2} \mathrm{CO}$ & [ppm] & 675 & 171 & 180 & 185 & 150 & 225 & $0.6 \%$ & $-6.0 \%$ \\
\hline Allene: $\mathrm{CH}_{2}=\mathrm{C}=\mathrm{CH}_{2}$ & [ppm] & 163 & 0 & 0 & 5 & 22 & 1 & $-7.9 \%$ & $-9.6 \%$ \\
\hline Propyne: $\mathrm{CH}_{3} \mathrm{C} \equiv \mathrm{CH}$ & [ppm] & 225 & 27 & 11 & 82 & 42 & 64 & $-1.7 \%$ & $0.1 \%$ \\
\hline Cyclopropane: $\mathrm{C}_{3} \mathrm{H}_{6}$ & {$[\mathrm{ppm}]$} & 0 & 0 & 0 & 67 & 1 & 30 & - & - \\
\hline Propene: $\mathrm{CH}_{3} \mathrm{CH}=\mathrm{CH}_{2}$ & {$[\mathrm{ppm}]$} & 967 & 562 & 45 & 669 & 87 & 340 & $-2.2 \%$ & $-1.7 \%$ \\
\hline Acetaldehyde: $\mathrm{CH}_{3} \mathrm{CHO}$ & {$[\mathrm{ppm}]$} & 85 & 126 & 661 & 165 & 31 & 276 & $-12.4 \%$ & $-7.3 \%$ \\
\hline Ethenol: $\mathrm{C}_{2} \mathrm{H}_{3} \mathrm{OH}$ & [ppm] & 1 & 4 & 20 & 3 & 1 & 6 & $-1.1 \%$ & $-1.9 \%$ \\
\hline Propane: $\mathrm{CH}_{3} \mathrm{CH}_{2} \mathrm{CH}_{3}$ & {$[\mathrm{ppm}]$} & 33 & 67 & 8 & 25 & 8 & 44 & $4.2 \%$ & $0.4 \%$ \\
\hline Dimethyl-ether: $\mathrm{CH}_{3} \mathrm{OCH}_{3}$ & {$[\mathrm{ppm}]$} & 0 & 0 & 10 & 0 & 6 & 0 & $-3.9 \%$ & $-2.1 \%$ \\
\hline Ethanol: $\mathrm{C}_{2} \mathrm{H}_{5} \mathrm{OH}$ & {$[\mathrm{ppm}]$} & 35 & 0 & 2854 & 0 & 0 & 23 & $1.1 \%$ & $-1.1 \%$ \\
\hline Formic-acid: $\mathrm{HCOOH}$ & {$[\mathrm{ppm}]$} & 22 & 0 & 0 & 0 & 0 & 0 & $-2.2 \%$ & $-1.7 \%$ \\
\hline Diacetylene: $\mathrm{C}_{4} \mathrm{H}_{2}$ & [ppm] & 0 & 0 & 0 & 6 & 14 & 0 & - & - \\
\hline Vinylacetylene: $\mathrm{HC} \equiv \mathrm{C}-\mathrm{CH}=\mathrm{CH}_{2}$ & [ppm] & 23 & 9 & 0 & 33 & 52 & 37 & $-21.3 \%$ & $-18.5 \%$ \\
\hline Butatriene: $\mathrm{H}_{2} \mathrm{C}=\mathrm{C}=\mathrm{C}=\mathrm{CH}_{2}$ & [ppm] & 0 & 0 & 11 & 1 & 0 & 0 & - & - \\
\hline 1,3-Butadiene: $\mathrm{H}_{2} \mathrm{C}=\mathrm{CH}-\mathrm{CH}=\mathrm{CH}_{2}$ & [ppm] & 77 & 97 & 1 & 338 & 28 & 710 & $2.2 \%$ & $2.0 \%$ \\
\hline 1-Butyne: $\mathrm{C}_{2} \mathrm{H}_{5} \mathrm{C} \equiv \mathrm{CH}$ & {$[\mathrm{ppm}]$} & 17 & 11 & 2 & 7 & 6 & 99 & $2.2 \%$ & $2.0 \%$ \\
\hline 2-Butyne: $\mathrm{CH}_{3} \mathrm{C} \equiv \mathrm{C}-\mathrm{CH}_{3}$ & [ppm] & 4 & 0 & 0 & 5 & 0 & 0 & - & - \\
\hline 1-Butene: $\mathrm{CH}_{2}=\mathrm{CHCH}_{2} \mathrm{CH}_{3}$ & [ppm] & 1442 & 330 & 2 & 281 & 44 & 187 & $2.0 \%$ & $2.6 \%$ \\
\hline Iso-butene: $\left(\mathrm{CH}_{3}\right)_{2} \mathrm{C}=\mathrm{CH}_{2}$ & [ppm] & 0 & 0 & 0 & 0 & 0 & 0 & $-2.2 \%$ & $-0.6 \%$ \\
\hline cis-2-Butene: $\mathrm{CH}_{3} \mathrm{CH}=\mathrm{CHCH}_{3}$ & [ppm] & 901 & 4 & 9 & 175 & 3 & 0 & $0.6 \%$ & $3.0 \%$ \\
\hline trans-2-Butene: $\mathrm{CH}_{3} \mathrm{CH}=\mathrm{CHCH}_{3}$ & {$[\mathrm{ppm}]$} & 0 & 0 & 0 & 0 & 0 & 20 & $0.6 \%$ & $3.0 \%$ \\
\hline Acetone: $\mathrm{CH}_{3} \mathrm{COCH}_{3}$ & {$[\mathrm{ppm}]$} & 106 & 0 & 3 & 4 & 3 & 9 & $1.7 \%$ & $1.0 \%$ \\
\hline Iso-butane: $\left(\mathrm{CH}_{3}\right)_{3} \mathrm{CH}$ & {$[\mathrm{ppm}]$} & 42 & 134 & 22 & 94 & 10 & 8 & $3.9 \%$ & $1.1 \%$ \\
\hline Allyl-alcohol: $\mathrm{CH}_{2}=\mathrm{CHCH}_{2} \mathrm{OH}$ & {$[\mathrm{ppm}]$} & 0 & 160 & 3 & 101 & 21 & 69 & $2.0 \%$ & $1.0 \%$ \\
\hline n-Butane: $\mathrm{CH}_{3}\left(\mathrm{CH}_{2}\right)_{2} \mathrm{CH}_{3}$ & [ppm] & 161 & 18 & 19 & 0 & 0 & 0 & $4.5 \%$ & $1.1 \%$ \\
\hline 2-Propanol: $\left(\mathrm{CH}_{3}\right)_{2} \mathrm{CHOH}$ & [ppm] & 16 & 5 & 113 & 11 & 5 & 0 & $2.0 \%$ & $1.4 \%$ \\
\hline Methyl-formate: $\mathrm{HCO}_{2} \mathrm{CH}_{3}$ & [ppm] & 0 & 67 & 0 & 105 & 182 & 104 & - & - \\
\hline 1,3-pentadiene: $\mathrm{CH}_{3} \mathrm{CH}=\mathrm{CHCH}=\mathrm{CH}_{2}$ & [ppm] & 57 & 6 & 0 & 26 & 0 & 2 & $3.1 \%$ & $1.9 \%$ \\
\hline 1,4-pentadiene: $\mathrm{CH}_{2}=\mathrm{CHCH}_{2} \mathrm{CH}=\mathrm{CH}$ & [ppm] & 0 & 3 & 0 & 33 & 1 & 6 & $-0.8 \%$ & $-0.9 \%$ \\
\hline Cyclopentene: $\mathrm{C}_{5} \mathrm{H}_{8}$ & {$[\mathrm{ppm}]$} & 22 & 13 & 0 & 6 & 0 & 143 & $3.4 \%$ & $4.7 \%$ \\
\hline
\end{tabular}




\begin{tabular}{|c|c|c|c|c|c|c|c|c|c|}
\hline & & 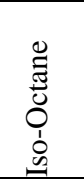 & 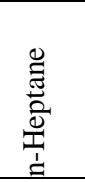 & 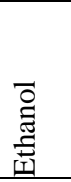 & 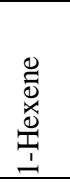 & 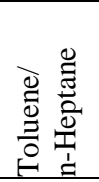 & 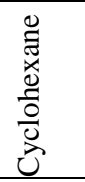 & & \\
\hline Species: Formula & & & & & & & & $\begin{array}{c}\Delta t_{i g n}(850 \mathrm{~K}, \\
15 \mathrm{bar})^{\mathrm{b}} \\
\end{array}$ & $\begin{array}{c}\Delta t_{\text {ign }}(950 \mathrm{~K}, \\
22 \text { bar })^{\mathrm{b}} \\
\end{array}$ \\
\hline Furan: $\mathrm{C}_{4} \mathrm{H}_{4} \mathrm{O}$ & [ppm] & 0 & 0 & 0 & 0 & 5 & 10 & $0.6 \%$ & $0.4 \%$ \\
\hline 1-Pentene: $\mathrm{CH}_{3}\left(\mathrm{CH}_{2}\right)_{2} \mathrm{CH}=\mathrm{CH}_{2}$ & [ppm] & 84 & 0 & 0 & 0 & 0 & 17 & $2.0 \%$ & $0.9 \%$ \\
\hline 2-Butenal: $\mathrm{CH}_{3} \mathrm{CH}=\mathrm{CHCHO}$ & [ppm] & 32 & 0 & 0 & 0 & 0 & 10 & $5.1 \%$ & $1.7 \%$ \\
\hline 2-Methyl-1-butene: $\mathrm{CH}_{3} \mathrm{CH}_{2} \mathrm{C}\left(\mathrm{CH}_{3}\right)=\mathrm{CH}_{2}$ & [ppm] & 0 & 70 & 0 & 26 & 2 & 32 & $-11.5 \%$ & $-7.2 \%$ \\
\hline 3-Methyl-1-butene: $\left(\mathrm{CH}_{3}\right) 2 \mathrm{CHCH}=\mathrm{CH}_{2}$ & [ppm] & 3 & 55 & 0 & 0 & 20 & 87 & $-15.7 \%$ & $-10.6 \%$ \\
\hline Methyl vinyl ketone: $\mathrm{CH}_{3} \mathrm{CCH}=\mathrm{CH}_{2}$ & [ppm] & 14 & 32 & 0 & 55 & 0 & 95 & $0.6 \%$ & $0.3 \%$ \\
\hline trans-2-Pentene: $\mathrm{C}_{2} \mathrm{H}_{5} \mathrm{CH}=\mathrm{CHCH}_{3}$ & [ppm] & 52 & 2 & 0 & 0 & 0 & 36 & $2.8 \%$ & $0.6 \%$ \\
\hline Methyl tert-butyl ether: $\left(\mathrm{CH}_{3}\right)_{3} \mathrm{COCH}_{3}$ & [ppm] & 9 & 0 & 0 & 0 & 0 & 0 & - & - \\
\hline Iso-butanal: $\left(\mathrm{CH}_{3}\right)_{2} \mathrm{CHCH}_{2} \mathrm{OH}$ & [ppm] & 37 & 0 & 0 & 0 & 0 & 0 & $2.0 \%$ & $-0.1 \%$ \\
\hline Tetrahydrofuran: $\mathrm{C}_{4} \mathrm{H}_{8} \mathrm{O}$ & [ppm] & 0 & 21 & 0 & 11 & 0 & 7 & $-5.1 \%$ & $-4.7 \%$ \\
\hline n-Pentane: $\mathrm{CH}_{3}\left(\mathrm{CH}_{2}\right)_{3} \mathrm{CH}_{3}$ & [ppm] & 13 & 41 & 0 & 4 & 7 & 0 & $1.7 \%$ & $0.6 \%$ \\
\hline 1-Butanol: $\mathrm{CH}_{3}\left(\mathrm{CH}_{2}\right)_{3} \mathrm{OH}$ & [ppm] & 1922 & 67 & 35 & 59 & 35 & 0 & $2.8 \%$ & $2.0 \%$ \\
\hline Iso-butanol: $\left(\mathrm{CH}_{3}\right)_{2} \mathrm{CHCHO}$ & [ppm] & 231 & 0 & 0 & 0 & 0 & 0 & $2.8 \%$ & $2.0 \%$ \\
\hline Benzene: $\mathrm{C}_{6} \mathrm{H}_{6}$ & [ppm] & 96 & 16 & 4 & 108 & 755 & 244 & $0.3 \%$ & $-0.3 \%$ \\
\hline 1,3-Cyclohexadiene: $\mathrm{C}_{6} \mathrm{H}_{8}$ & [ppm] & 14 & 0 & 0 & 10 & 4 & 59 & $4.8 \%$ & $1.7 \%$ \\
\hline 1,3-Hexadiene: $\mathrm{C}_{2} \mathrm{H}_{5} \mathrm{CH}=\mathrm{CHCH}=\mathrm{CH}_{2}$ & [ppm] & 18 & 0 & 0 & 2 & 0 & 0 & $-8.7 \%$ & $-5.4 \%$ \\
\hline 1,5-Hexadiene: $\mathrm{H}_{2} \mathrm{C}=\mathrm{CHCH}_{2} \mathrm{CH}_{2} \mathrm{CH}=\mathrm{CH}_{2}$ & [ppm] & 12 & 0 & 0 & 15 & 3 & 42 & $-5.1 \%$ & $-5.6 \%$ \\
\hline Cyclohexene: $\mathrm{C}_{6} \mathrm{H}_{10}$ & [ppm] & 12 & 5 & 0 & 17 & 4 & 221 & $0.3 \%$ & $-0.7 \%$ \\
\hline 1-Hexene: $\mathrm{CH}_{3}\left(\mathrm{CH}_{2}\right)_{3} \mathrm{CH}=\mathrm{CH}_{2}$ & [ppm] & 48 & 33 & 0 & 911 & 5 & 1 & $-3.4 \%$ & $-4.1 \%$ \\
\hline n-Hexane: $\mathrm{CH}_{3}\left(\mathrm{CH}_{2}\right)_{4} \mathrm{CH}_{3}$ & [ppm] & 0 & 7 & 0 & 0 & 0 & 0 & $-3.1 \%$ & $-0.9 \%$ \\
\hline Cyclohexane: $\mathrm{C}_{6} \mathrm{H}_{12}$ & [ppm] & 4 & 18 & 0 & 83 & 1 & 2078 & - & - \\
\hline 1-Pentanol: $\mathrm{CH}_{3}\left(\mathrm{CH}_{2}\right)_{4} \mathrm{OH}$ & [ppm] & 49 & 0 & 0 & 9 & 0 & 0 & - & - \\
\hline Iso-pentanol: $\left(\mathrm{CH}_{3}\right)_{2} \mathrm{CHCH}_{2} \mathrm{CH}_{2} \mathrm{OH}$ & [ppm] & 0 & 110 & 0 & 0 & 0 & 0 & - & - \\
\hline tert-Pentanol: $\mathrm{CH}_{3} \mathrm{CH}_{2} \mathrm{C}\left(\mathrm{CH}_{3}\right)_{2} \mathrm{OH}$ & [ppm] & 25 & 0 & 0 & 0 & 0 & 0 & - & - \\
\hline Toluene: $\mathrm{C}_{6} \mathrm{H}_{5} \mathrm{CH}_{3}$ & [ppm] & 15 & 0 & 0 & 11 & 3417 & 0 & $0.8 \%$ & $0.7 \%$ \\
\hline Phenol: $\mathrm{C}_{6} \mathrm{H}_{5} \mathrm{OH}$ & [ppm] & 0 & 0 & 0 & 0 & 76 & 0 & $-9.8 \%$ & $-5.3 \%$ \\
\hline 1-Heptyne: $\mathrm{CH}_{3}\left(\mathrm{CH}_{2}\right)_{4} \mathrm{C} \equiv \mathrm{CH}$ & [ppm] & 10 & 1 & 0 & 3 & 4 & 17 & - & - \\
\hline 2,5-Dimethylfuran: $\left(\mathrm{CH}_{3}\right)_{2} \mathrm{C}_{4} \mathrm{H}_{2} \mathrm{O}$ & [ppm] & 7 & 0 & 0 & 0 & 4 & 8 & - & - \\
\hline Methylcyclohexane: $\mathrm{C}_{6} \mathrm{H}_{11} \mathrm{CH}_{3}$ & [ppm] & 69 & 2 & 0 & 0 & 1 & 18 & $-5.3 \%$ & $-4.0 \%$ \\
\hline Ethyl-propenoate: $\mathrm{CH}_{2}=\mathrm{CHCOOC}_{2} \mathrm{H}_{5}$ & [ppm] & 22 & 0 & 0 & 0 & 0 & 0 & - & - \\
\hline Methyl-crotonate: $\mathrm{CH}_{3} \mathrm{CH}=\mathrm{CHCOOCH}_{3}$ & [ppm] & 0 & 135 & 0 & 0 & 13 & 0 & - & - \\
\hline n-Heptane: $\mathrm{CH}_{3}\left(\mathrm{CH}_{2}\right)_{5} \mathrm{CH}_{3}$ & [ppm] & 4 & 1941 & 0 & 3 & 335 & 0 & $-4.5 \%$ & $-1.4 \%$ \\
\hline Methyl-isobutyrate: $\left(\mathrm{CH}_{3}\right)_{2} \mathrm{CHCOOCH}_{3}$ & [ppm] & 5 & 1 & 0 & 14 & 10 & 6 & - & - \\
\hline Phenylacetylene: $\mathrm{C}_{6} \mathrm{H}_{5} \mathrm{CCH}$ & [ppm] & 23 & 0 & 0 & 0 & 20 & 0 & $4.2 \%$ & $3.0 \%$ \\
\hline Styrene: $\mathrm{C}_{6} \mathrm{H}_{5} \mathrm{CH}=\mathrm{CH}_{2}$ & [ppm] & 0 & 0 & 0 & 5 & 57 & 0 & $0.3 \%$ & $-0.3 \%$ \\
\hline Benzaldehyde: $\mathrm{C}_{6} \mathrm{H}_{5} \mathrm{CHO}$ & [ppm] & 0 & 0 & 0 & 0 & 13 & 0 & $-31.7 \%$ & $-20.3 \%$ \\
\hline Ethylbenzene: $\mathrm{C}_{6} \mathrm{H}_{5} \mathrm{C}_{2} \mathrm{H}_{5}$ & [ppm] & 2 & 0 & 0 & 0 & 169 & 0 & $4.8 \%$ & $-0.7 \%$ \\
\hline p-Xylene: $\mathrm{C}_{6} \mathrm{H}_{4}\left(\mathrm{CH}_{3}\right)_{2}$ & [ppm] & 3 & 0 & 0 & 0 & 0 & 0 & $4.5 \%$ & $3.3 \%$ \\
\hline 3-Propyl-1-cyclopentene: $\mathrm{C}_{8} \mathrm{H}_{14}$ & [ppm] & 18 & 0 & 0 & 0 & 0 & 0 & $5.1 \%$ & $3.7 \%$ \\
\hline 1-Octene: $\mathrm{CH}_{3}\left(\mathrm{CH}_{2}\right)_{5} \mathrm{CH}=\mathrm{CH}_{2}$ & [ppm] & 133 & 0 & 0 & 0 & 0 & 0 & $8.1 \%$ & $4.6 \%$ \\
\hline Benzyl-alcohol: $\mathrm{C}_{6} \mathrm{H}_{5} \mathrm{CH}_{2} \mathrm{OH}$ & [ppm] & 0 & 0 & 0 & 0 & 8 & 0 & $4.2 \%$ & $-2.6 \%$ \\
\hline Iso-octane: $\left(\mathrm{CH}_{3}\right)_{2} \mathrm{CHCH}_{2} \mathrm{C}\left(\mathrm{CH}_{3}\right)_{3}$ & [ppm] & 2140 & 10 & 0 & 0 & 0 & 0 & $3.7 \%$ & $1.0 \%$ \\
\hline
\end{tabular}




\begin{tabular}{|c|c|c|c|c|c|c|c|c|c|}
\hline & & 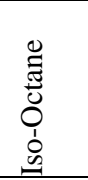 & 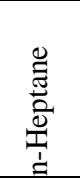 & 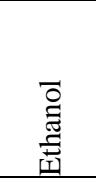 & 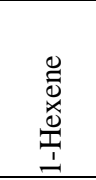 & 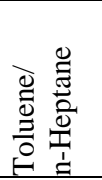 & 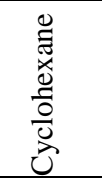 & & \\
\hline Species: Formula & & & & & & & & $\begin{array}{c}\Delta t_{i g n}(850 \mathrm{~K}, \\
15 \mathrm{bar})^{\mathrm{b}}\end{array}$ & $\begin{array}{c}\Delta t_{\text {ign }}(950 \mathrm{~K}, \\
22{\text { bar })^{\mathrm{b}}}\end{array}$ \\
\hline Indene: $\mathrm{C}_{9} \mathrm{H}_{8}$ & [ppm] & 0 & 0 & 0 & 0 & 20 & 0 & $4.8 \%$ & $3.4 \%$ \\
\hline Indane: $\mathrm{C}_{9} \mathrm{H}_{10}$ & {$[\mathrm{ppm}]$} & 0 & 0 & 0 & 0 & 8 & 0 & $4.8 \%$ & $3.3 \%$ \\
\hline n-Propylbenzene: $\mathrm{C}_{6} \mathrm{H}_{5} \mathrm{CH}_{2} \mathrm{CH}_{2} \mathrm{CH}_{3}$ & {$[\mathrm{ppm}]$} & 0 & 0 & 0 & 0 & 8 & 0 & - & - \\
\hline n-Nonane: $\mathrm{CH}_{3}\left(\mathrm{CH}_{2}\right)_{7} \mathrm{CH}_{3}$ & [ppm] & 0 & 0 & 0 & 0 & 10 & 0 & - & - \\
\hline${ }^{\mathrm{a}}$ Hydrogen: $\mathrm{H}_{2}$ & [ppm] & 4118 & 4120 & 11078 & 3680 & 2726 & 5275 & $0.8 \%$ & $0.0 \%$ \\
\hline${ }^{\mathrm{a} C}$ Carbon monoxide: $\mathrm{CO}$ & {$[\mathrm{ppm}]$} & 8616 & 7705 & 17341 & 13414 & 9930 & 13171 & $0.3 \%$ & $0.1 \%$ \\
\hline${ }^{\text {a}}$ Methane: $\mathrm{CH}_{4}$ & [ppm] & 4180 & 2144 & 4543 & 3173 & 1069 & 1897 & $1.1 \%$ & $0.9 \%$ \\
\hline
\end{tabular}

Note: The value reported in the two rightmost columns is the change in the ignition delay time $\left(\Delta t_{i g n}\right)$ from neat PRF60 at $\varphi=1$ to that when $5 \%$ of the test species (by mole) is mixed with PRF60 at $\varphi=1$.

${ }^{a}$ Experimental mole fractions reported by Wolk et al. [12], measured using gas chromatography.

${ }^{\mathrm{b}}$ The baseline values for PRF60 are $t_{i g n}(850 \mathrm{~K}, 15 \mathrm{bar})=35.6 \mathrm{~ms}$ and $t_{i g n}(950 \mathrm{~K}, 22 \mathrm{bar})=6.99 \mathrm{~ms}$. 

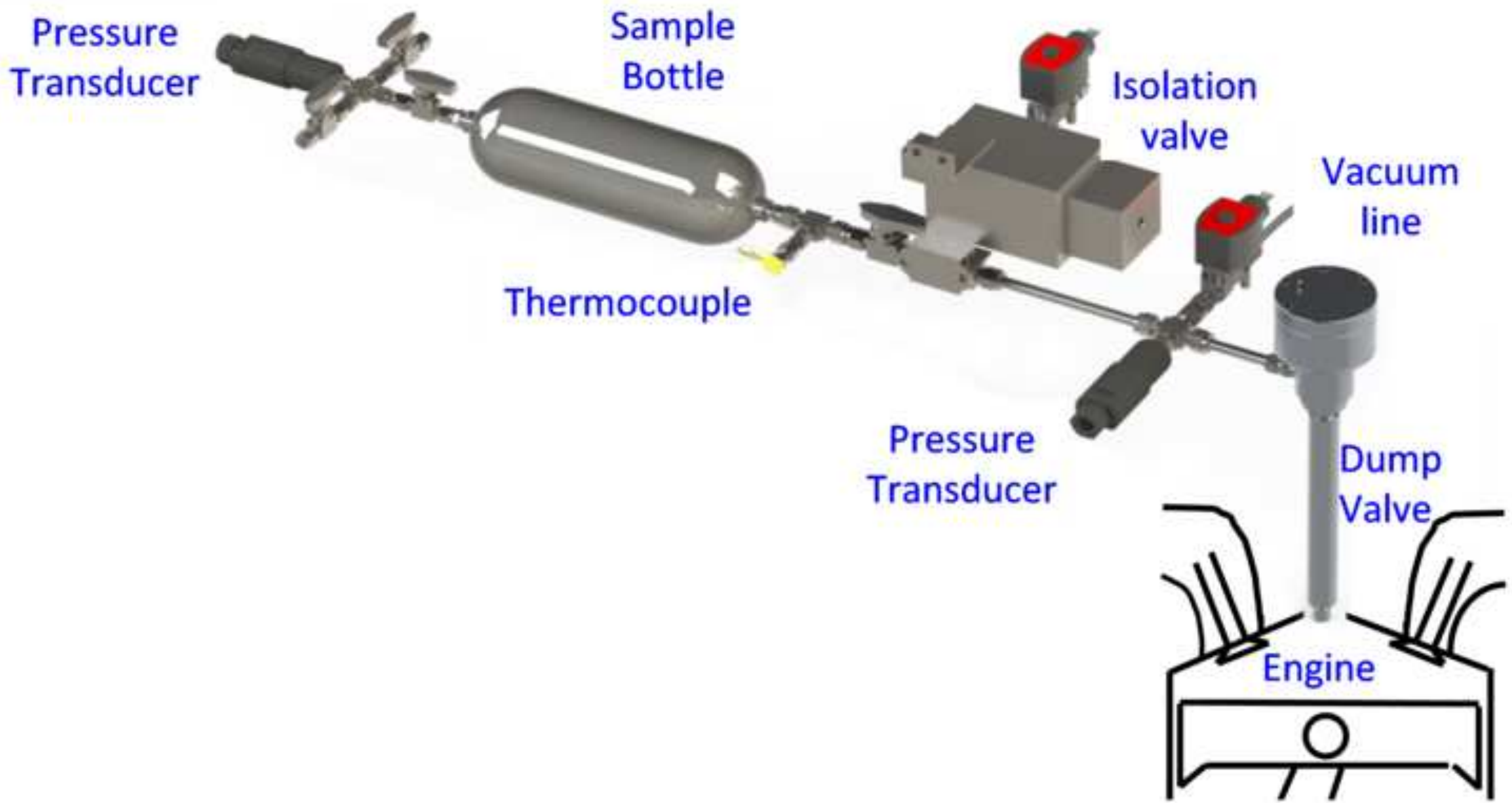

Thermocouple 


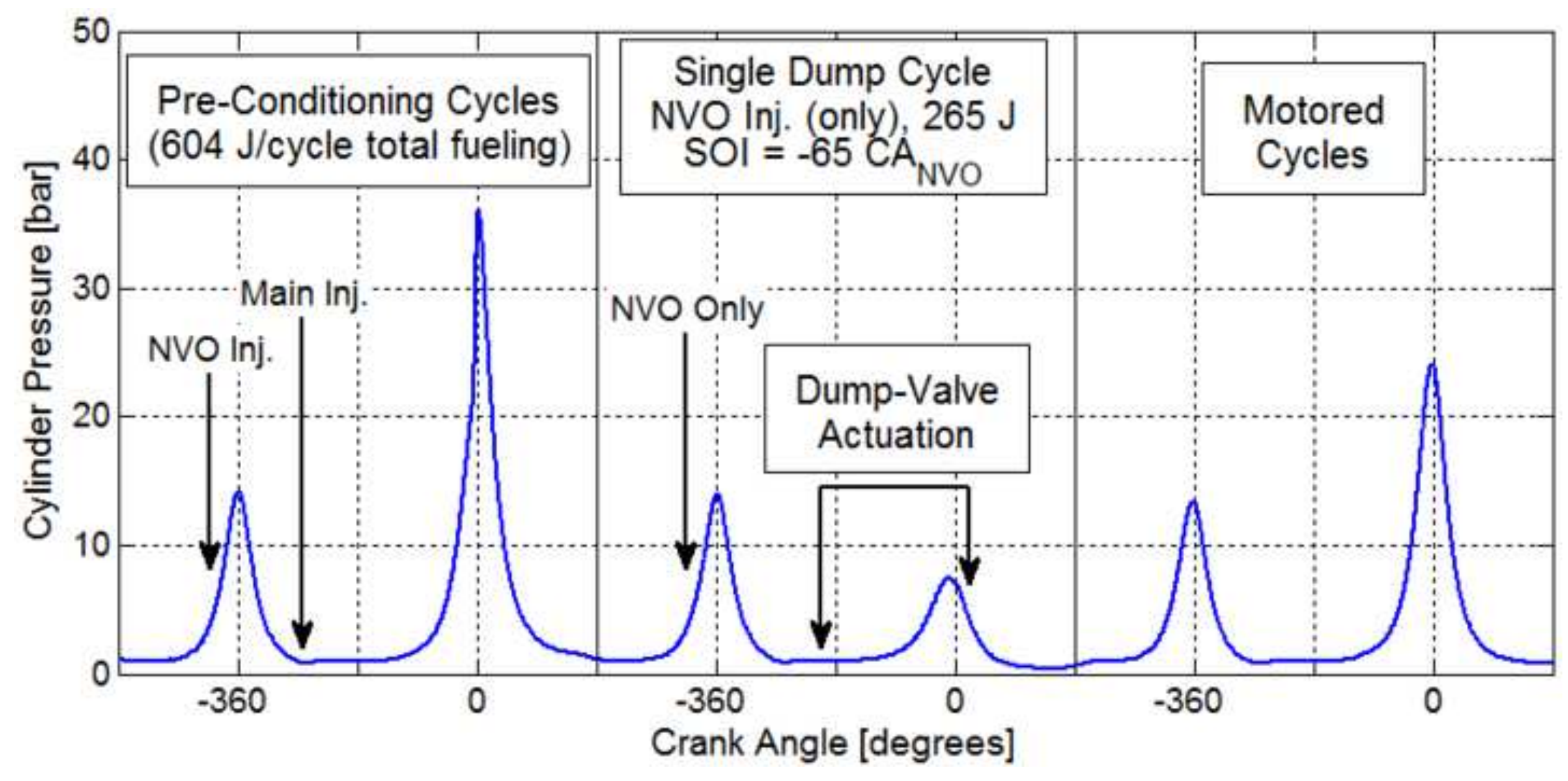




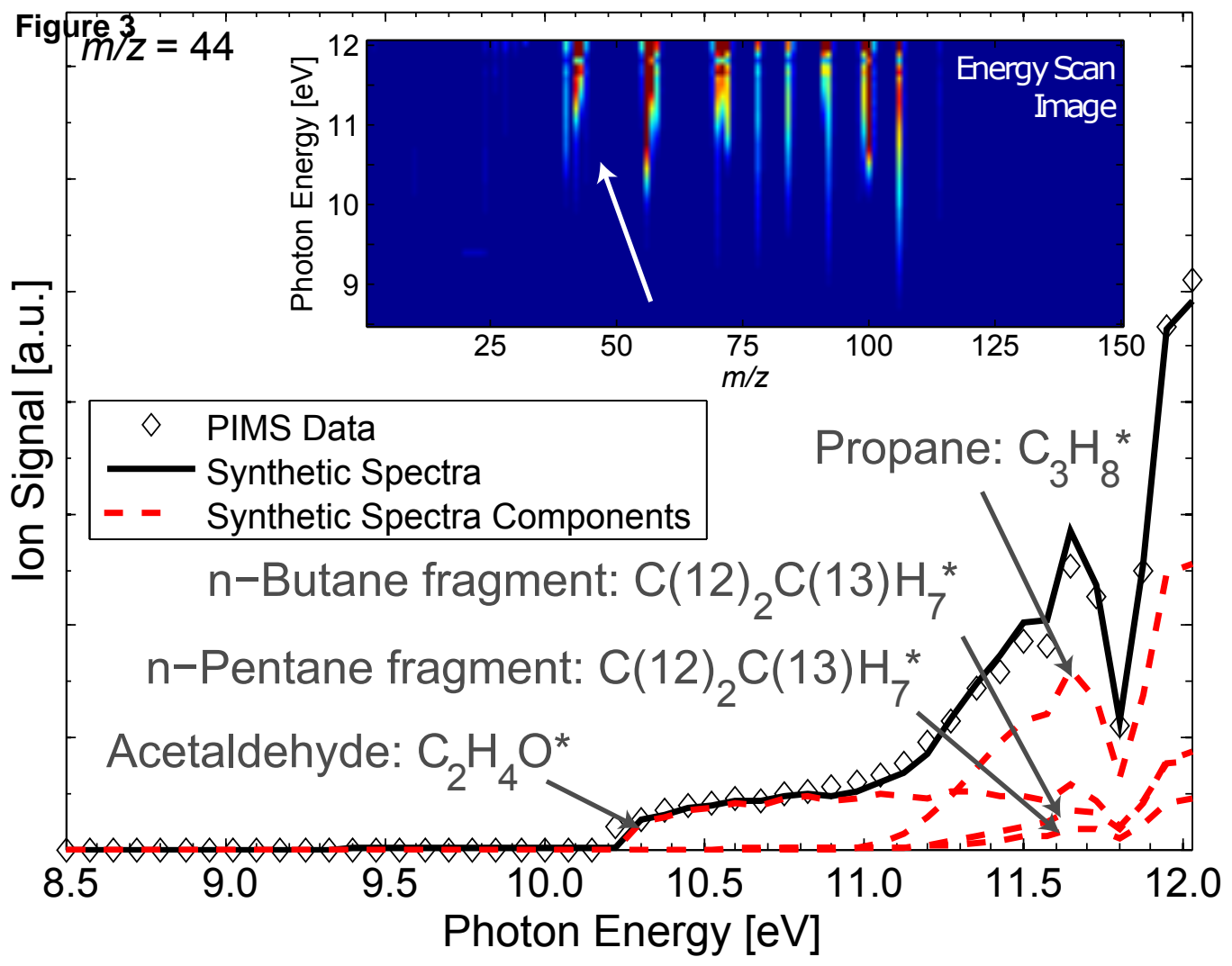




\section{Figur $\longdiv { \text { e } 4 }$}

Cycle-of-interest NVO/Main Fuel Energy: 265/135 J

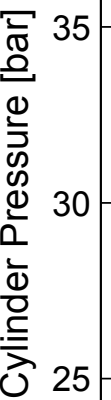
NVO SOI: $-65^{\circ}$ Fuel: iso-octane
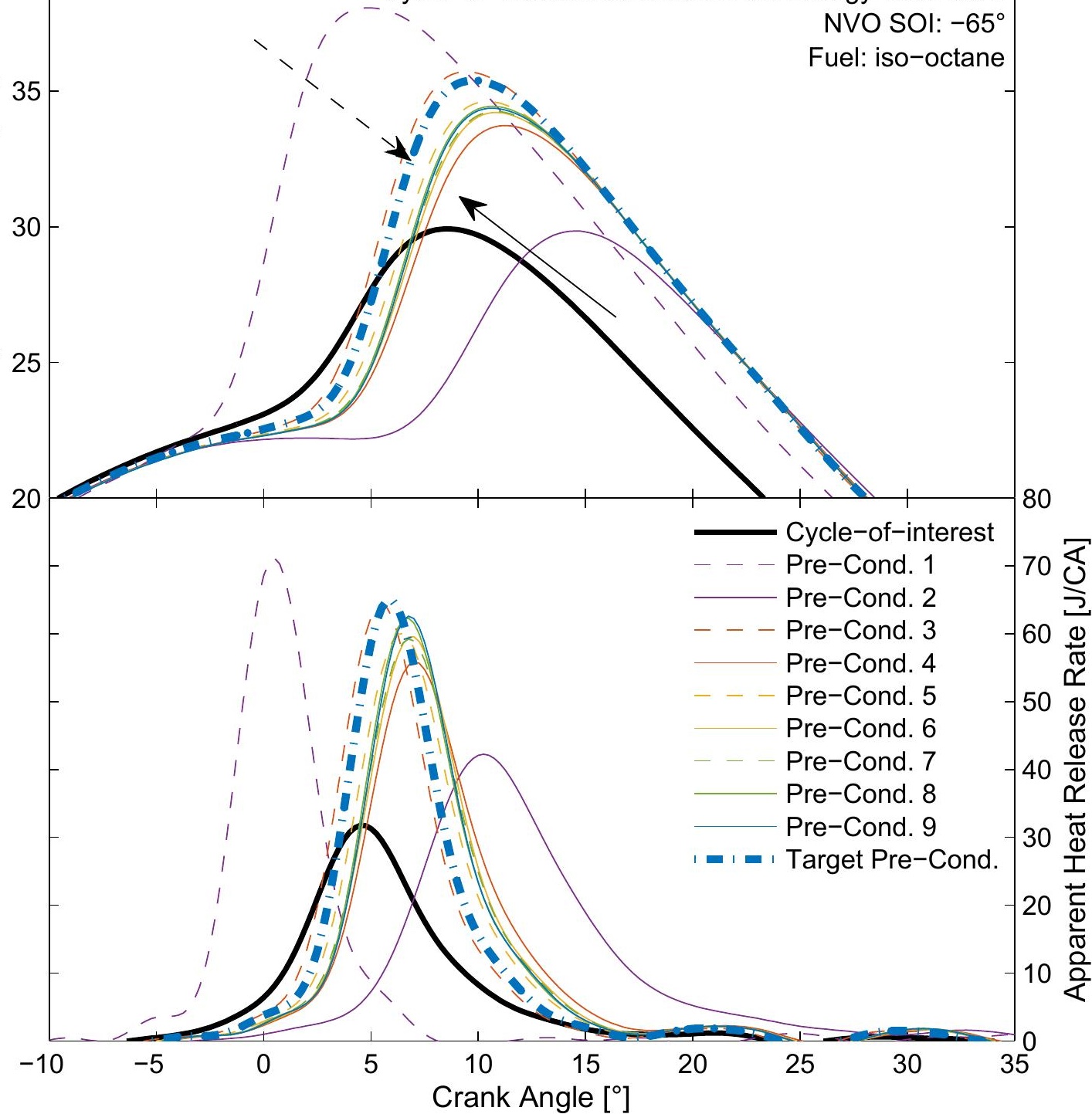
Figưure 5

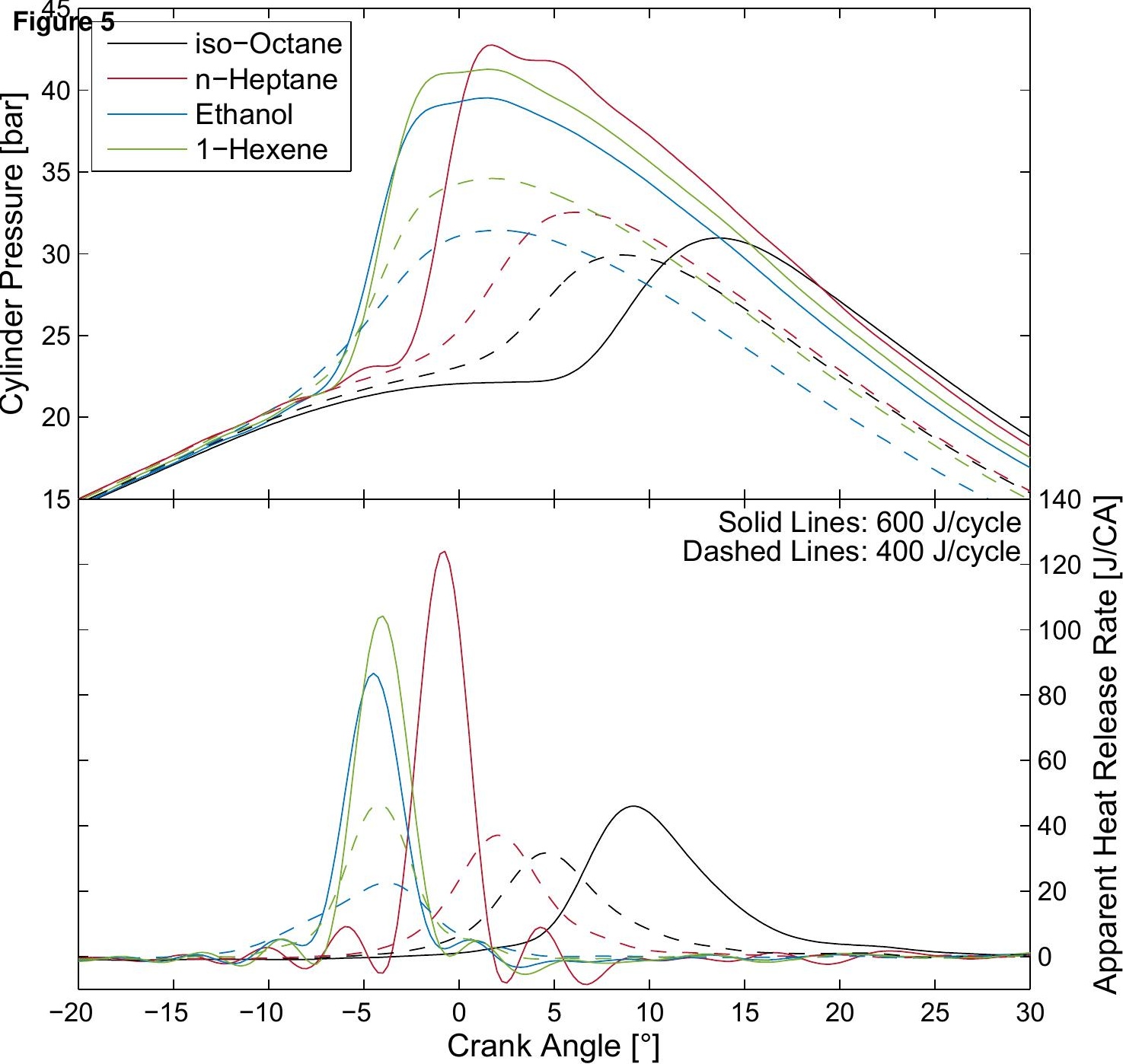


Figure 7

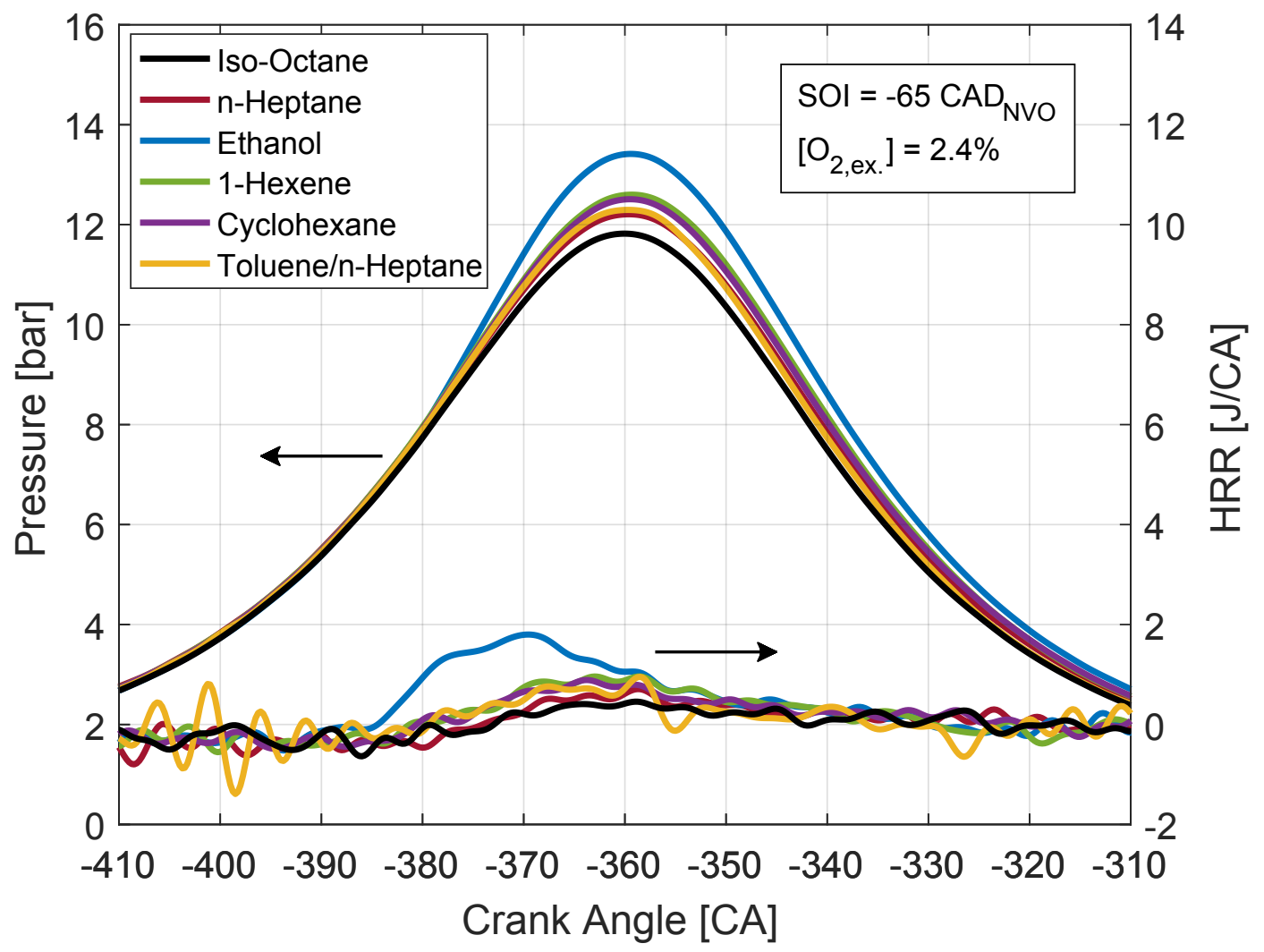




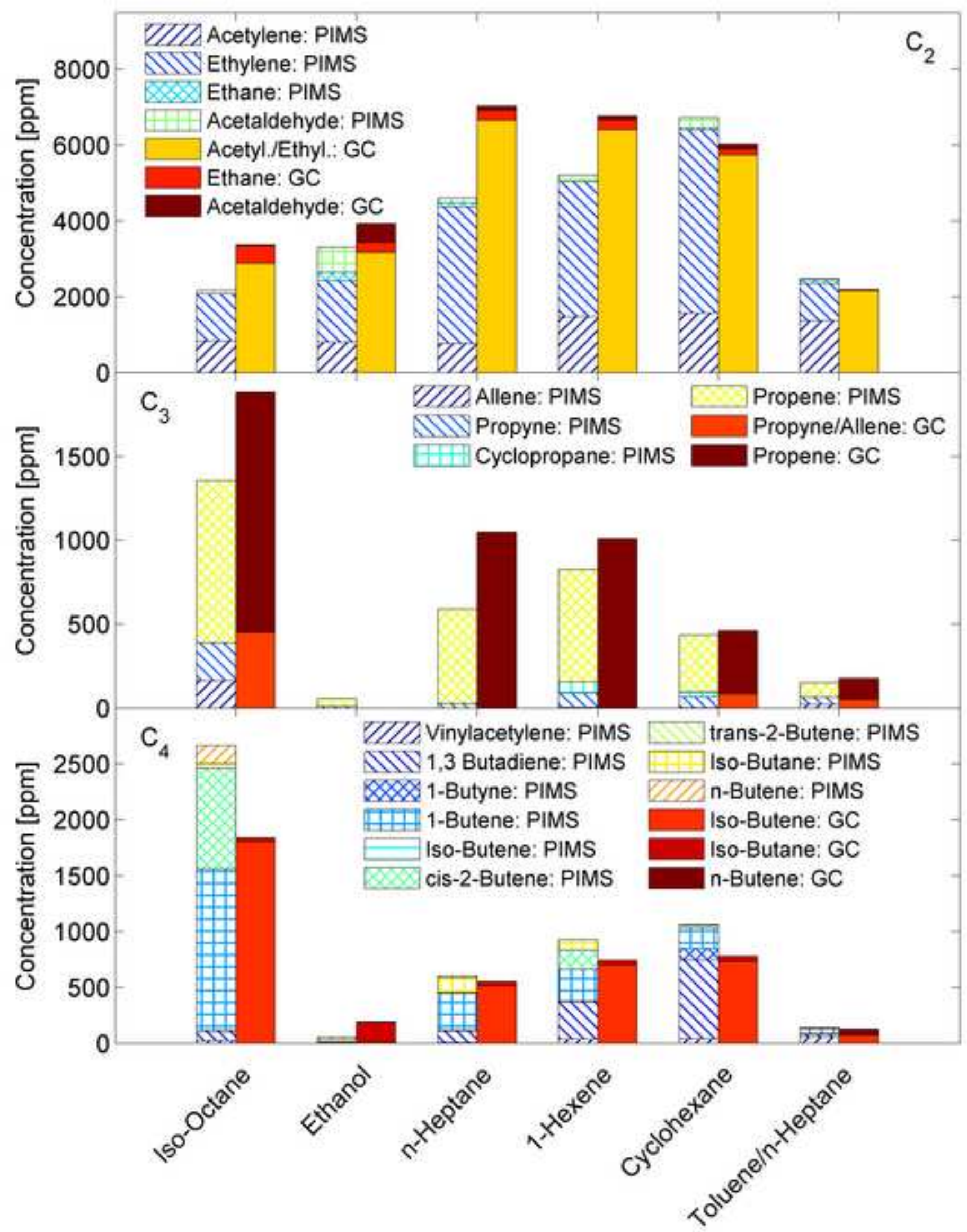



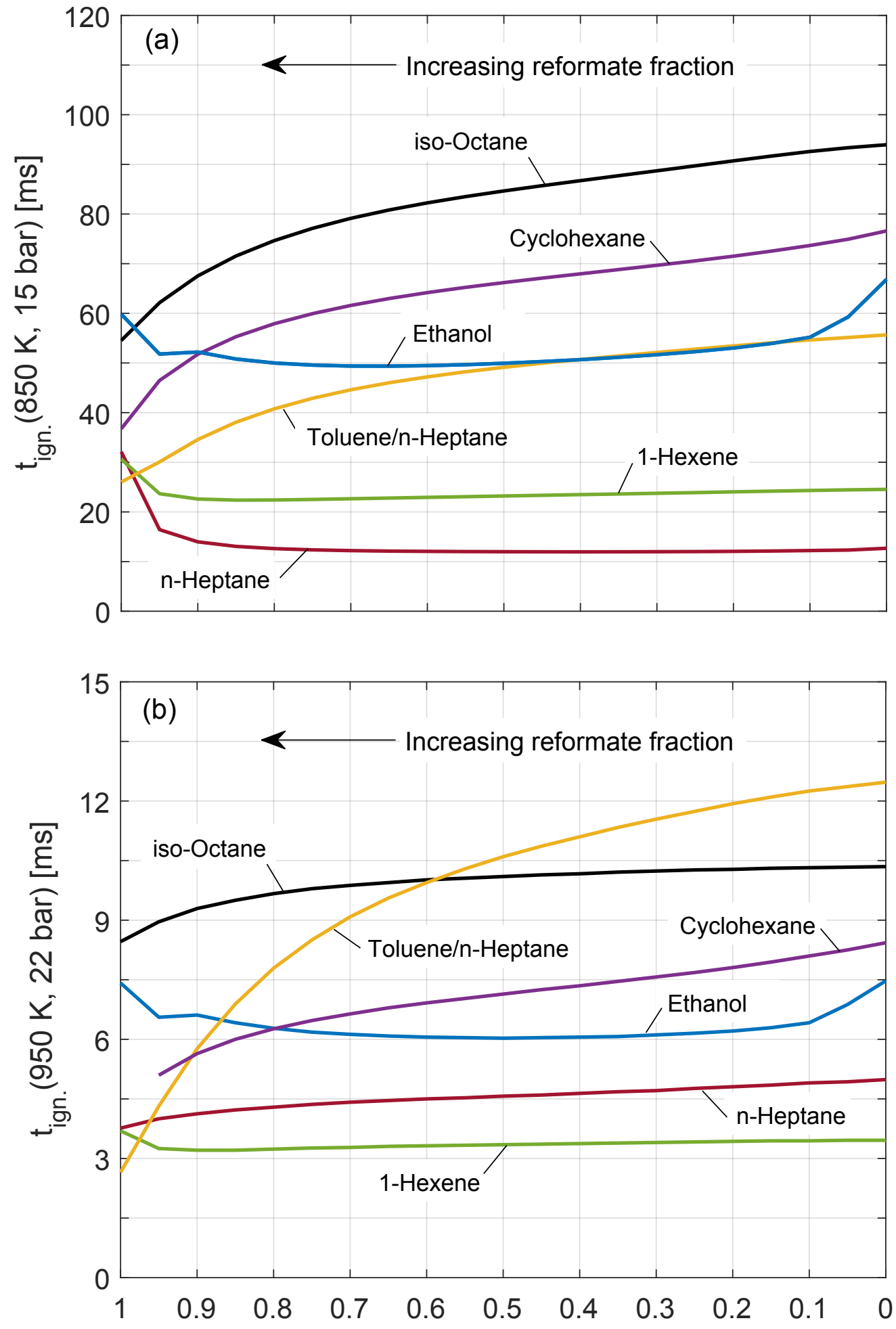

Mass Fraction of Reformate in Fuel-Reformate Blend 


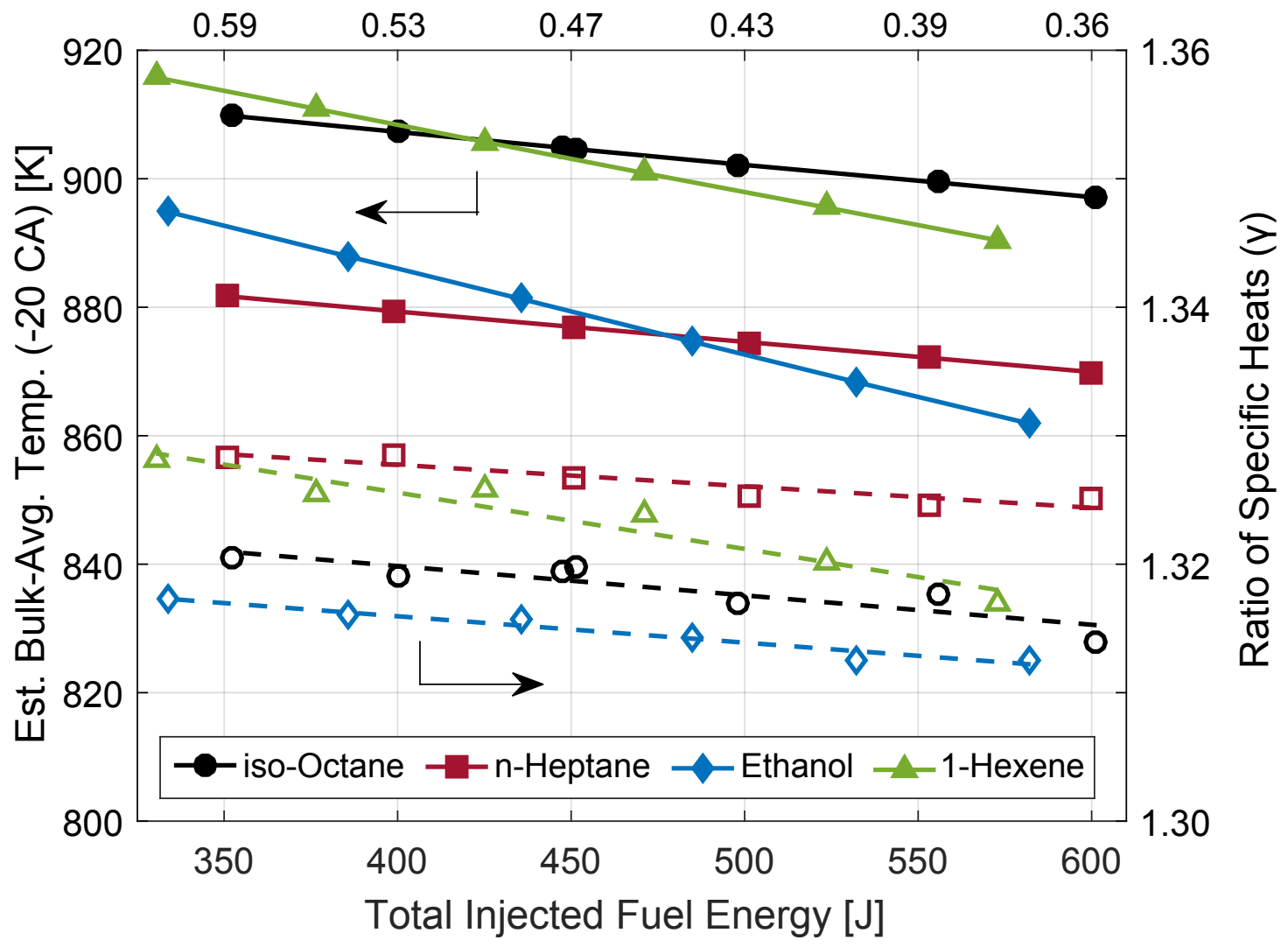



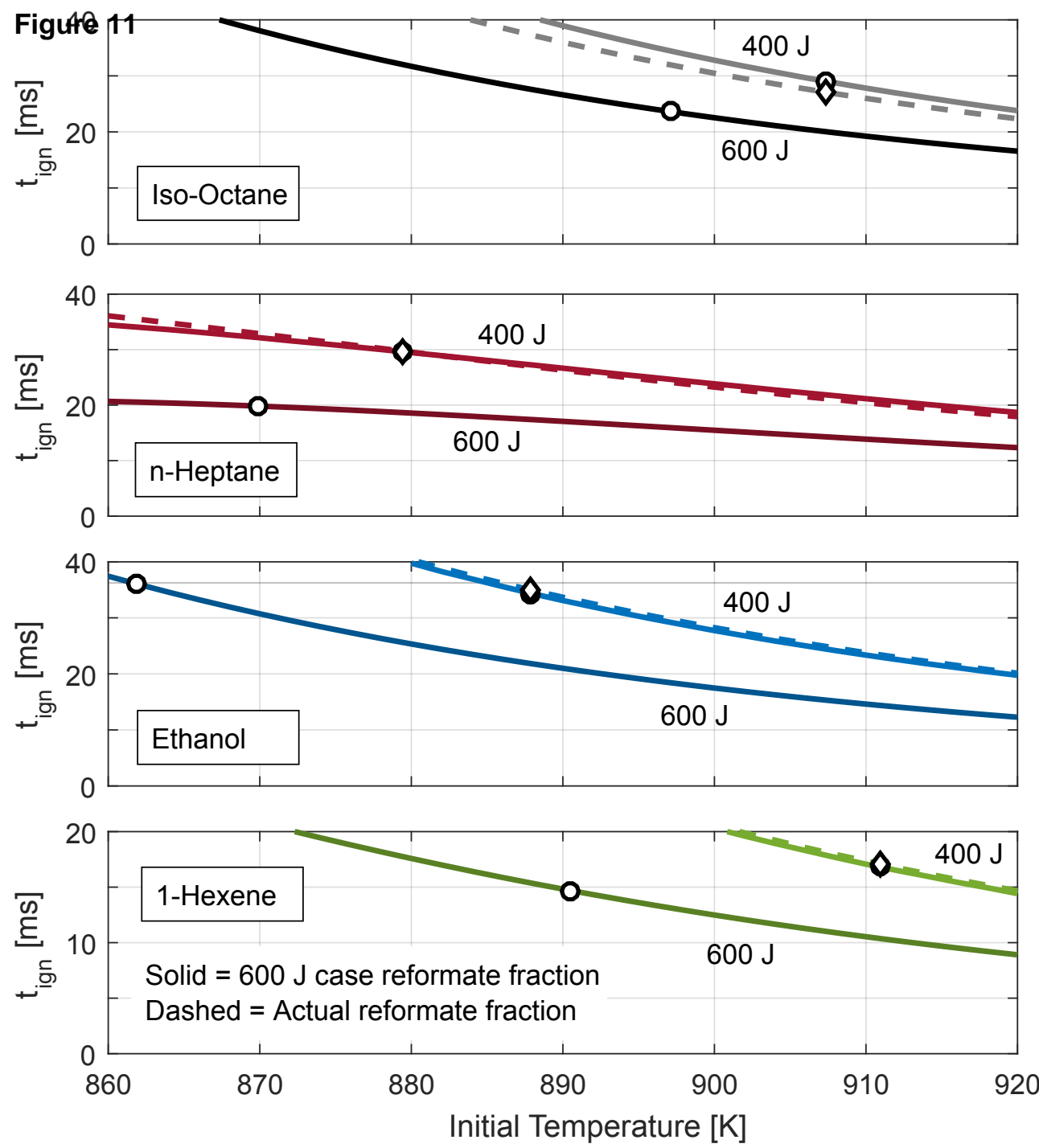